Florida International University FIU Digital Commons

2005

\title{
Shoot architecture and growth in the south Florida wet prairie macrophyte, Eleocharis cellulosa
}

Shanaz Baksh

Florida International University

DOI: $10.25148 /$ etd.FI14050416

Follow this and additional works at: https://digitalcommons.fiu.edu/etd

Part of the Biology Commons

\section{Recommended Citation}

Baksh, Shanaz, "Shoot architecture and growth in the south Florida wet prairie macrophyte, Eleocharis cellulosa" (2005). FIU

Electronic Theses and Dissertations. 1379.

https://digitalcommons.fiu.edu/etd/1379

This work is brought to you for free and open access by the University Graduate School at FIU Digital Commons. It has been accepted for inclusion in FIU Electronic Theses and Dissertations by an authorized administrator of FIU Digital Commons. For more information, please contact dcc@fiu.edu. 
FLORIDA INTERNATIONAL UNIVERSITY

Miami, Florida

SHOOT ARCHITECTURE AND GROWTH IN THE SOUTH FLORIDA WET

PRAIRIE MACROPHYTE, ELEOCHARIS CELLULOSA

A thesis submitted in partial fulfillment of the

requirements for the degree of

MASTER OF SCIENCE

in

BIOLOGY

by

Shanaz Baksh

2005 
To: Interim Dean Mark Szuchman

College of Arts and Sciences

This thesis, written by Shanaz Baksh, and entitled Shoot Architecture and Growth in the South Florida Wet Prairie Macrophyte, Eleocharis cellulosa, having been approved in respect to style and intellectual content, is referred to you for judgment.

We have read this thesis and recommend that it be approved.

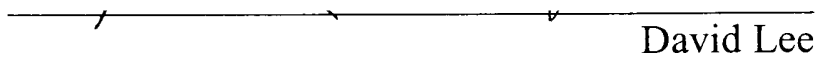

Jack Fisher

Date of Defense: June 28, 2005

The thesis of Shanaz Baksh is approved.

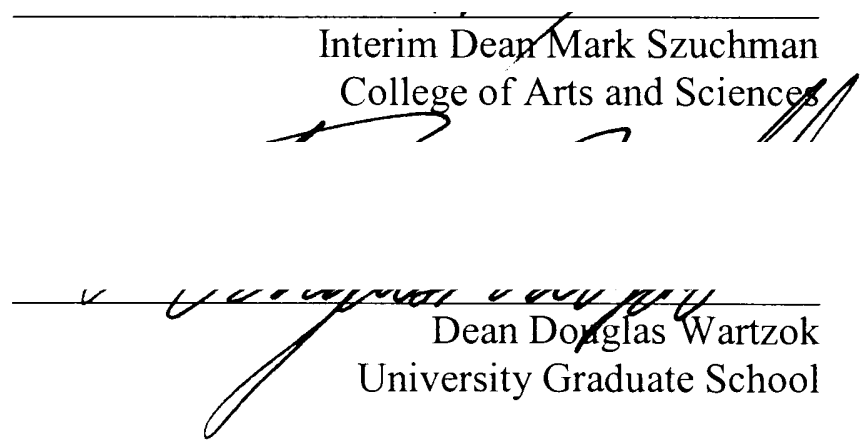

Florida International University, 2005 


\section{DEDICATION}

I dedicate this thesis to my parents. My parents have been exemplary role models.

Their words of encouragement and wisdom have provided a positive influence on my life and have taught me that great satisfaction comes from hard work. I will always be thankful for their support. 


\section{ACKNOWLEDGMENTS}

I would like to thank my major professor and advisor, Dr. Jennifer Richards, for all her guidance and support. Her good spirit and invaluable instruction provided a pleasurable environment of learning. I would also like to thank my committee members, Drs. Jack Fisher and David Lee, for their constructive comments on my project as well as my thesis. I am also thankful to the Florida Center for Analytical Electron Microscopy (FCAE), the Seagrass lab and the FIU Biology Department research greenhouse for helping me to carry out my project. I am especially grateful to my lab for all their help and for always providing a joyful work climate. I would like to thank my friends and family for their support, especially my sister for always being there to talk. Her thoughtful gestures have helped me to get through stressful times. Finally, I would like to thank my husband. Not only has he provided lots of love and continuous support throughout the years, he has also acted as my field assistant in this project. I could not have completed my project without his help. 


\begin{abstract}
OF THE THESIS
SHOOT ARCHITECTURE AND GROWTH IN THE SOUTH FLORIDA

WET PRAIRIE MACROPHYTE, ELEOCHARIS CELLULOSA
\end{abstract}

by

Shanaz Baksh

Florida International University, 2005

Miami, Florida

Professor Jennifer Richards, Major Professor

Eleocharis cellulosa is a dominant macrophyte in Everglades wet prairie communities. The development of the shoot system in the genus has been described as sympodial but with an unusual adnation of the horizontal and vertical shoots. The growth pattern of E. cellulosa was studied from field collected plants and plants grown in the greenhouse. Plants were extracted and measurements of horizontal and vertical shoot were taken. Dissections, paraffin sectioning and SEM's were used to examine shoot structure in early developmental stages. E. cellulosa was transplanted from the field to the greenhouse and different levels of Nitrogen and Phosphorus were added to determine how it responded phenotypically. Dissections and microscopy showed that growth of the vertical shoots of E. cellulosa is sympodial, while growth of the horizontal shoots is mixed, beginning monopodially then transforming to sympodial growth. Additions of nutrients did not have any effect on the morphology of E. cellulosa. 


\section{TABLE OF CONTENTS}

CHAPTER

PAGE

I INTRODUCTION

II SHOOT DIMORPHISM 2

2.1 Introduction 3

2.1a Terminology 6

2.2 Materials and Methods $\quad 7$

2.2a Mature shoot morphology $\quad 7$

2.2b Determination of sympodial vs. monopodial growth 7

2.2c Statistical analysis $\quad 8$

2.3 Results

2.3a Pattern of shoot architecture. General growth pattern 9

$2.3 \mathrm{~b}$ Growth of culms 9

$2.3 \mathrm{c}$ Growth of the horizontal stem $\quad 10$

2.3d Seasonal variation in shoot morphology 12

2.4 Discussion

2.5a Shoot architecture $\quad 13$

$\begin{array}{ll}2.5 \mathrm{~b} \text { Phenological variation } & 15\end{array}$

2.5 Literature cited

III EFFECTS OF NUTRIENT ADDITIONS ON MORPHOLOGY OF E.

CELLULOSA

3.1 Introduction $\quad 43$

3.2 Materials and Methods $\quad 45$

$\begin{array}{ll}\text { 3.3a Statistical analysis } & 47\end{array}$

3.3 Results

3.3a Soil nutrient analyses $\quad 48$

3.3b Architectural responses to nutrient addition 48

3.3c Plant tissue nutrient response to nutrient addition 49

3.3d Biomass partitioning $\quad 49$

3.3e Comparison of morphology of greenhouse-grown plants to field collected plants 49

3.4 Discussion

3.4a Soil nutrient analyses $\quad 50$

$3.4 \mathrm{~b}$ Architectural responses to nutrient addition $\quad 50$

$3.4 \mathrm{c}$ Biomass partitioning $\quad 51$

3.5 Literature cited 


\section{LIST OF TABLES}

TABLE

PAGE

1.1. Summary of statistics for seasonal effects

2.1. Significance values of treatment effects on nutrient content in E. cellulosa

2.2. Summary of statistics for treatment effects on E. cellulosa growth

2.3. Summary of statistics for biomass under different treatments

2.4. Mean biomass allocation to different plant parts

2.5. Comparison of fertilization experiment to field data 


\section{LIST OF FIGURES}

FIGURE

PAGE

1.1. Model of growth for E. acicularis and E. palustris 21

1.2. Pattern of growth for E. cellulosa 22

1.3. Shoot system of E. cellulosa

1.4. HS to VS transition 24

1.5. Average internode length for two seasons 25

1.6. Comparison of internode length 26

1.7. Different developmental stages of E. cellulosa 27

1.8. Cross section of E. cellulosa shoot 29

1.9. SEMs of developing sympodia in E. cellulosa 30

1.10. SEMs of individual culm and axillary bud in E. cellulosa 31

1.11. Cross section of $E$. cellulosa shoot after HS to VS transition 32

1.12. Cross section of E. cellulosa shoot prior to HS to VS transition 33

1.13. Close up of cross section from Figure 1.7. 34

1.14. Cross section of a bud in the axil of B2 35

1.15. Cross section of a bud from B2 36

1.16. HS to VS transition showing peg-like shoot 37

1.17. Regression of culm diameter vs. culm length for two seasons 38

1.18. Regression of leaf bract 2 length vs. leaf bract 3 length for two seasons 39

1.19. Patterns of growth for E. cellulosa 40

2.1. Biomass allocation on different plant structures 61 


\section{INTRODUCTION}

I have written this thesis as two chapters that study the shoot dimorphism of Eleocharis cellulosa in the south Florida Everglades. Each chapter has its own introduction, materials and methods, results, discussion and literature cited sections. The tables and figures are also numbered for each chapter and are the final sections of each chapter.

In chapter 1 shoot dimorphism in E. cellulosa is examined in field collected plants in order to determine the species' morphology and growth pattern. The culm and horizontal shoot are described morphologically. Seasonal variation in growth and morphology is also examined over one wet season and one dry season.

In chapter 2 effects of increased low levels of nitrogen and phosphorus on $E$. cellulosa growth and morphology is examined to determine how it responds phenotypically to different nutrient levels. Comparisons were made between my results from the greenhouse experiment and field-collected data from chapter 1. 
Chapter 1

The Morphology And Development Of Shoot Dimorphism In E. Cellulosa (Cyperaceae) 


\section{INTRODUCTION}

Species in the genus Eleocharis are important components of the Everglades ecosystem and are among the most common plants in the natural communities of south Florida (Stober et al. 2001). Eleocharis, commonly known as spikerush, belongs to the sedge family Cyperaceae. There are 29 species of Eleocharis in Florida; they occur in diverse habitats but usually are found in aquatic or wetland environments, both brackish and freshwater (Tobe et al. 1998, Godfrey and Wooten 1979). Eleocharis species are usually rooted and emergent, but some species may form floating or submersed mats (Tobe et al. 1998). Plants are perennial and persist throughout the year (Godfrey and Wooten 1979). In the Everglades, Gunderson (1994) recognized an open marsh community dominated by Eleocharis cellulosa that he designated as spikerush and sedge flats (Davis 1994).

Species of Eleocharis can differ in habit and growth form (Godfrey and Wooten 1979). Eleocharis species can grow as annuals or perennials and can have tufted or rhizomatous growth forms (Tobe et al. 1998). All species have both horizontal (plagiotropic) stems and vertical (orthotropic) stems. Plants do not produce photosynthetic leaves as adults; all the leaves are membranous bracts, so the upright stems are the photosynthetic organs for the plant (Tucker 1987). The tufted forms produce upright stems close together and have short or long horizontal shoots. The rhizomatous forms often have solitary or a few upright stems and produce long horizontal shoots between these stems (Godfrey and Wooten 1971). Eleocharis spreads by growth of its horizontal stems, as well by the dispersal of seeds and tubers (Stevens 1980). The aboveground upright stem is unbranched and has sheathing bracts that resemble hyaline 
leaf bases. The upright stem terminates in a spikelet (Tucker 1987, Bruhl 1995). The tufted and rhizomatous habits occupy and exploit their environments and display photosynthetic surfaces differently, thus each have distinct ecological and evolutionary strategies.

The difference between tufted and rhizomatous forms of Eleocharis species depends on the length and number of horizontal internodes and the positions and rates of production of vertical stems. Presumably, a tufted species has little internodal elongation and/or few internodes formed between the production of vertical stems, while a rhizomatous species forms many and/or long internodes between the production of vertical stems. The nature of these differences, however, has not been well-documented in the genus.

Similarly, the pattern of branching or branch architecture has not been adequately documented for any species of Eleocharis. Some species of the genus have been described as having an unusual sympodial growth form in which the upright stems are part of the main shoot, while the horizontal stems are axillary buds that are fused with the main stem prior to that stem's becoming orthotropic and the axillary branch continuing horizontal growth (Fig. 1.1, Mora 1960, Walters 1950). This type of growth has been described in some other genera of sedges (Goetghebeur 1985, Mora 1960, Walters 1950) and may be a general growth pattern in the Cyperaceae. However, modern investigations of this unusual developmental pattern are lacking.

Growth of the shoot system in Eleocharis cellulosa could be either monopodial or sympodial (Fig. 1.2). In monopodial growth, shoot apices bear leaves that subtend axillary buds; these buds grow out as branches, while the shoot apex continues growth of 
the main axis (Fig. 1.1A). For example, in a monopodial model of E. cellulosa growth, the horizontal shoot is the main shoot apex bearing bracts with axillary buds, while the axillary buds grow out as vertical shoots. This is depicted in Mora's (1960) model, with the added hypothesis that the axillary bud axis is fused to the main stem axis, thus explaining the position of the determinate stem below a bract, rather than in an axillary position (Fig. 1.1.A.) In sympodial shoot growth, the main axis is formed by a succession of apices that become determinate, and growth of the main axis is taken over by an axillary bud (Fig. 1.1B). In a sympodial model of growth for Eleocharis, the horizontal shoot would turn up and terminate in a vertical shoot; growth of a new horizontal shoot, as well as additional vertical shoots, would develop from axillary buds. Walters (1950) hypothesized this type of growth in Eleocharis palustris, as well as fusion of the main shoot and removal shoot in the lower part of their axes.

Branch architecture has been studied in a number of rhizomatous species (Bell and Tomlinson 1980, Bell 1991) but has not been described for E. cellulosa. Because architecture is correlated with advantages to the survival, reproduction and foraging in Eleocharis (Routledge 1987), knowing this species' architecture will help us understand its success in the Everglades wet prairies. Since Eleocharis is one of the major species in wetland communities of the Everglades, knowledge of its growth and morphology is essential to interpreting this species' response to restoration.

The purpose of this study was to describe shoot growth and branching patterns in E. cellulosa. In the Everglades of south Florida this species produces clusters of a few orthotropic stems separated by long horizontal stems. I used morphological and developmental studies to establish whether growth in E. cellulosa is sympodial or 
monopodial and to determine when in development buds are determined as either determinate upright shoots or indeterminate horizontal shoots. I also documented patterns of seasonal variation in horizontal shoot and vertical shoot morphology for E. cellulosa in the Everglades wet prairie community.

Terminology: Various terms have been used to describe stem architecture in Eleocharis. Throughout this paper I use the following terms to designate different parts of the shoot system: a "culm" is the upright photosynthetic shoot; a "horizontal stem" (HS) is the plagiotropic portion of the shoot system; a "vertical stem" (VS) is the orthotropic portion of the shoot that has short, relatively thick internodes. The adult plant does not have photosynthetic leaves but produces membranous bracts on the shoots or smaller but thicker bracts on the inflorescence. These are referred to as "bracts" (B) and are numbered in the order of their production along an axis when this is useful (i.e. B1, B2, B3, etc.). Similarly, when referring to culms or branching units produced along a VS, these are numbered successively from older to younger (e.g. S1, S2 ...). Internodes associated with bracts are the internodes below the bract node. The term genet refers to a genetically distinct individual, i.e., an individual that was not produced vegetatively. A ramet is an individual member of a genet. Ramets are produced vegetatively. 


\section{MATERIALS AND METHODS}

Mature Shoot Morphology. Eleocharis cellulosa shoot structure was investigated in plants from a natural population on the Florida International University-Singeltary

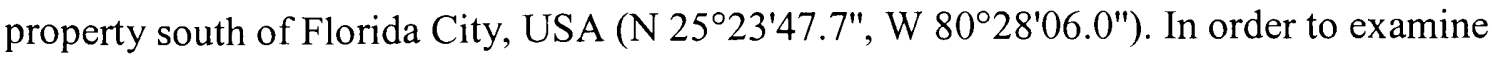
variation in architecture between the wet and dry season, thirty plants were collected from the site at the end of the wet season (October 2003) and an additional 30 were collected at the end of the dry season (April 2004). Plants collected were producing erect shoots and had produced at least one HS that had turned up.

These samples were taken back to the lab, dissected and their morphology was mapped. To determine how internode length varied along a shoot and how this variation was associated with the production of vertical vs. horizontal shoots, length and number of internodes were measured along the entire HS until it turned upright and started to produce a VS and culms. The length and diameter of up to three recently matured culms on each sample were recorded. Lengths were measured with a mm ruler but diameters were measured with electronic calipers. These culms were sampled two culms back from obviously immature culms. The number and length of bracts on the upright culms were measured. Axils of all bracts were examined with a dissecting microscope for the presence of axillary buds.

Determination of Sympodial vs. Monopodial Shoot Growth. Whether shoots are sympodial or monopodial was determined by examining developing leaves and apices (1) in dissections observed with a dissecting microscope, (2) in material prepared for and viewed with scanning electron microscopy (SEM), and (3) in developing shoots that were embedded in paraffin, sectioned and examined with a compound light microscope. 
For compound light microscopy, horizontal shoot apices that were producing upright shoots were harvested from the shoots collected at the FIU-Singletary property and fixed in Craf III solution (Berlyn and Miksche 1976). This material was supplemented with material of developing HSs grown outdoors in an artificial pond in Miami, FL. Apices were embedded in paraffin, serially sectioned at $5 \mu \mathrm{m}$, stained with haematoxylin-safranin, and examined with a compound light microscope. The relationship of shoot apices, leaves and axillary buds in early development was documented photographically with a digital camera. For SEM, fixed and dissected apices were critical-point dried in $\mathrm{CO}_{2}$, coated with gold-palladium, and examined in a JOEL JSM 5900LV scanning electron microscope (Peabody, Massachusetts, USA) at the Florida Center for Analytical Electron Microscopy at FIU. Material was viewed at 20kV. Paraffin sections and SEMs were examined for evidence of the adnation process that has been described for upright and horizontal shoots of Eleocharis species (Walters 1950) and for sympodial vs. monopodial growth. These data, in conjunction with knowledge of the branching architecture determined above, allowed me to distinguish among models for sympodial and monopodial growth.

Statistical analysis. All statistics were performed using the SPSS 13.0 (SPSS Inc., Chicago, IL) statistical package for Windows and Microsoft Windows XP Excel. To assess seasonal differences in morphology, ANOVA tests of significance were used. Regression analysis using Excel was used to assess relationships between morphological variables. 


\section{RESULTS}

Pattern of shoot architecture. General growth pattern. E. cellulosa plants had a horizontal stem (HS) that turned vertically to produce upright photosynthetic stems, the culms, from the thickened VS (Fig. 1.3A, 1.4). Roots developed along the HS and on the VS below the culms; they were typically associated with nodes. In field-collected plants the HSs were $120 \pm 62 \mathrm{~mm}$ in length $(\mathrm{N}=60)$. Individual internodes averaged $23 \pm 17 \mathrm{~mm}$ $(\mathrm{N}=317)$, although internode length varied along the HS, being initially short, increasing in length, and then decreasing as the apex turned up (Fig.1.5, 1.6). After the stem turned vertically, internodes were $1 \mathrm{~mm}$ or less in length, and the stem thickened (Fig. 1.4A). The vertical part of the shoot system produced a variable number of photosynthetic culms, while new horizontal stems were initiated on the lower parts of the VS (Fig. 1.3B, 1.4B). The HS nodes produced hyaline bracts that ensheathed the stem (Fig. 1.4A), but these bracts were ephemeral and were present only as tattered remnants or were absent on older HSs. No buds were visible in the axils of these bracts when examined by dissecting microscope.

Growth of the culms. Growth of the vertical shoot system was sympodial. Each shoot apex on the vertical stem produced 4 bracts, and then the shoot tip either aborted or produced an inflorescence. The first 3 bracts $-\mathrm{B} 1$, which was the prophyll, B2 and B3 (Fig. 1.7A) - were closed hyaline bracts that surrounded the base of the photosynthetic culm, but only B2 and B3 were visible on the mature culm. All 3 bracts had short internodes $<1 \mathrm{~mm}$ in length. $\mathrm{B} 3$ was longer than $\mathrm{B} 2(\mathrm{~B} 2=44.8 \pm 23.1(\mathrm{~N}=93), \mathrm{B} 3=$ $117.8 \pm 56.6(\mathrm{~N}=93)$. The internode above $\mathrm{B} 3$ elongated into the photosynthetic culm (Fig. 1.3, 1.7B). The tip of this culm bore a reduced bract, B4, that was thickened and 
photosynthetic in vegetative shoots (Fig. 1.7B). The apex of these shoots produced aborted inflorescences that remained enclosed by B4 (Fig. 1.7C). In flowering shoots this apex expanded, maturing bracts with short internodes between them. The bracts subtended bisexual flowers that were aggregated into the inflorescence spike (Fig. 1.7D).

The first bract or prophyll on an upright culm, B1, had an axillary bud (Fig. 1.8). The bud in the axil of B1 reiterated the vertical shoot, thus, this axillary bud produced a prophyll (B1) that subtended an axillary bud, B2, B3 and B4. The internode below B4 expanded into the photosynthetic culm. Thus, the vertical shoot consisted of a sympodial unit that had 4 bracts and an elongated photosynthetic B4 internode which was the culm, an aborted inflorescence and a B1 axillary bud that reiterated the sympodial unit. Each sympodium produced a B1 axillary bud that grew into another sympodium, which in turn produced its own B1 axillary bud. This sympodial structure was apparent both in the SEMs of the upright stem (Fig. 1.9 and 1.10) and in the paraffin sections (Fig.1.8, 1.11, $1.12,1.13)$.

Growth of the horizontal stem. The B2 bracts could also subtend axillary buds (Fig. 1.14). When they were present, these buds grew out as horizontal stems. Initial growth of the HS was from the B2 axillary bud and was monopodial (Figure 1.14), but this phase of growth lasted for a relatively short segment of the shoot. Initially, multiple bracts surrounded the HS with no buds present in the axils of these bracts (Fig. 1.15). The sympodial system was not initiated at the beginning of HS growth (Fig.1.15). Dissections and sections of the HS showed that after an initial phase of growth in which 3 to 5 leaves were produced, sympodial growth was initiated. Early sympodial units had small, undeveloped culms (Fig. 1.4A, 1.16). This culm peg was present just above the 
node on the more distal portions of HSs. A signal that sympodial growth had begun was the presence of this peg-like structure on the surface of the horizontal shoot. Distal internodes of mature HSs had a small peg-like structure at the distal end of an internode, immediately below the next node (Fig 1.4A). This structure was adjacent to the median portion of the HS bract. Sections of immature HSs showed that these peg-like structures had 2 ensheathing bracts and then a small cylindrical shoot (Fig. 1.11, 1.12, 1.13). The exact point along the horizontal shoot where growth became sympodial was variable. The length and number of internodes on the HS was also variable (Table 1.1).

Dissections showed that on the HS a number of sympodia were produced with aborted culms. In the transition from monopodial to sympodial growth, the initial sympodia did not produce fully expanded culms (Fig. 1.11, 1.12). Culms on successivelyproduced sympodia were slightly larger than the previous shoots and rounder in cross section (Fig. 1.11, 1.12). A slide showing cross-sections of the HS sampled before it had started growing vertically showed the same arrangement, but the structures were smaller and more tightly packed (Fig.1.11 compared to 1.12). Successively produced culms were larger until shoots expanded photosynthetic culms and developed normally (Fig. 1.3.). The axillary bud produced from Bl of the first sympodium produced the second sympodium. The axillary bud produced from $\mathrm{B} 1$ of the second sympodium produced the third sympodium in the transition to vertical growth. After a series of sympodia were produced with successively shorter and more upright internodes, a VS with photosynthetic culms was established (Fig. 1.8). During this transition to vertical growth, several horizontal internodes that were the B2 internodes of sympodial units were produced. The original apex of the horizontal shoot that was growing monopodially thus 
terminated and gave way to sympodial growth. This sympodial growth started before the vertical shoot was produced, but the photosynthetic culms on these shoots did not expand until the stem turned erect and the B2 internodes remained short.

Seasonal variation in shoot morphology. Morphology of the entire shoot system varied significantly between the southern Florida wet season and the dry season (Table 1.1). Plants sampled in October, the wet season, had significantly longer, wider culms with longer bracts than plants sampled in April, the dry season (Table 1.1). The wet season plants also produced more HS internodes and the average length of the median HS internode was greater (Table 1.1). When a two-way ANOVA was used to compare internode lengths with the length of the first, middle and final HS internodes as dependent variables and the internode position on the horizontal shoot and season as fixed factors, the means of the lengths of each internode and differences in internode position between seasons were not significant. $(\mathrm{F}=1.631, \mathrm{P}=>0.01, \mathrm{~N}=180$, ANOVA test.) The wet season plants produced longer internodes but plants in both seasons produced shorter internodes initially and subsequently-produced internodes were longer. Internode length decreased before the horizontal shoot turned up and produced photosynthetic culms (Table 1.1, Fig 1.5).

Culm lengths and diameters of plants sampled at the end of the wet season (October) were not significantly correlated $\left(\mathrm{r}^{2}=0.03\right)$, but were significantly correlated in the dry season (April), $\left(\mathrm{r}^{2}=0.60\right)$ (Fig. 1.17). The lengths of $\mathrm{B} 2$ and $\mathrm{B} 3$ also were not as strongly correlated in October, $\mathrm{r}^{2}=0.07$, as they were in April $\left(\mathrm{r}^{2}=0.54\right)$ (Fig. 1.18). 


\section{DISCUSSION}

Shoot architecture: Growth of the vertical shoots of E. cellulosa is sympodial, while growth of the horizontal shoots is mixed, beginning monopodially then transforming to sympodial growth. The stereotypical shoot system appears to be well defined and repetitive with the same number of basal bracts, the same internode that elongates, and the same buds that grow out either horizontally or vertically. The entire vertical shoot system is reproductive. Presumably, environmental conditions control whether or not inflorescences on culms expand. In many monocotyledons, it is common to find shoot dimorphism of vegetative branches (Fisher 1973). Most herbaceous perennials duplicate their apical meristems through branching. Duplication of their meristems allows them to continue growing, causing some of these rhizomatous plants to spread or expand in space and potentially live forever through vegetative reproduction (Bell and Tomlinson 1980).

Experiments on species in the Cyperaceae, such as Eriophorum angustifolium and Eleocharis palustris, have shown their horizontal shoot growth to be sympodial (Phillips 1953, Walters 1950). Horizontal shoots from these species had internodes bearing scale leaves with axillary buds. In the case of E. angustifolium, these axillary buds grew out to produce daughter horizontal shoots that continued sympodial growth (Phillips 1953). In E. palustris each horizontal shoot produced one internode and then terminated with the production of upright shoots. The axillary bud from one of these shoots grew out to continue the horizontal growth. The type of growth in E. palustris was described as a series of sympodial units that were mistaken for monopodial growth due to a fusion of the upright and underground shoot (Walters 1950). Although studies specific to $E$. 
cellulosa are limited, the results presented here show that E. cellulosa has both monopodial and sympodial stages or phases of growth (Fig. 1.19). I found no evidence for the type of axis fusion described for E. palustris (Walters 1950).

Shoot growth in E. cellulosa is dimorphic. The HS of E. cellulosa has bracts. The first-produced bracts do not subtend axillary buds and the horizontal growth is produced by a single apex, thus this phase of horizontal growth differs from the regular pattern of sympodial growth produced by the rest of the shoot system. This part of the shoot system is also unbranched. The evidence presented here, however, shows termination of this initial monopodial phase by maturation of this axis into an under-developed culm. The growth of this HS shoot is then taken over by an axillary bud. This aborted culm marks initiation of the sympodial system in E. cellulosa. The HS produced after the switch to sympodial growth has shorter internodes, and bracts now subtend axillary buds that grow out as sympodial units. Well defined uninterrupted meristems have been found at the internodes of horizontal shoots in E. cellulosa with localized distal meristematic regions in the internodes (Fisher and French, 1978). In contrast, the aerial axes produce intercalary meristems at the base of the elongated internodes (Fisher and French, 1978). The point where the internodes on the horizontal shoots of $E$. cellulosa change from uninterrupted meristems to intercalary meristems may coincide with the end of the monopodial system and the beginning of the sympodial system. Intercalary meristems are responsible for elongation of the stems in grasses (Bell 1991). The culms of E. cellulosa can expand or not expand inflorescences and appear vegetative, but they are all determinate, and the vertical shoot system is renewed by an axillary bud from the B1 bract on a culm; this bud grows out as a new culm. 
Culms can also produce a second vegetative axillary bud outside the sympodial growth pattern. This axillary bud arises from B2 and grows out to be a horizontal shoot (Fig. 1.3). Like growth in E. cellulosa, horizontal shoots in grasses usually develop from basal lateral buds of the leafy shoot (Fisher 1973). These buds are normally axillary (Tomlinson 1973). Evidence from these studies supports the conclusion that horizontal branching in E. cellulosa develops from an axillary bud of an upright shoot.

In E. palustris, through dissections of rhizomes and observations of seedling development, Walters (1950) determined the growth of the horizontal shoot to be sympodial. He observed that the horizontal shoot had a groove along the internode, just behind the node, and that cross-sections of the internode immediately below the node showed 2 distinct vascular systems. He interpreted these observations to show that the internode was formed by fusion of the culm and rhizome axis. In E. palustris each internode along the horizontal shoot turned up to produce a vertical shoot with culms (Walters 1950). This type of growth is different from E. cellulosa, where growth of the horizontal shoot begins monopodially and continues for up to 8 nodes (Fig. 1.6). The horizontal shoot of E. cellulosa produced 4 or 5 internodes through monopodial growth, then the apex terminated. Sympodial growth replaced monopodial growth in the horizontal shoot, gradually producing a vertical shoot and culms by an axillary bud that expanded and continued the plant axis.

Phenological variation. Fluctuating water levels are characteristic of the change in seasons in south Florida (Davis 1994). Plants of E. cellulosa transferred from deep water to shallow water had shoots that died quickly. When shallow water shoots were transferred to deep water, shoots elongated rapidly (Edwards et al.2003). Total shoot 
length of E. cellulosa was greater in flooded conditions than in water regimes that were drained or waterlogged (Busch et al. 2004). Results presented here found culm length and diameter and bract length to be greater at the end of the wet season (October 2003) than at the end of the dry season (April 2004). Thus, these field data corroborate the experimental data of Edwards et al. (2003) and provide evidence that E. cellulosa adjusts shoot length throughout the year in response to water level. Correlation results show that length and diameter of individual culms were more strongly related at the end of the dry season than at the end of the wet season (Table 1.1, Fig. 1.17). The length of leaf bracts on each culm were also more strongly correlated to culm diameter at the end of the dry season than in the end of the wet season (Figure 1.18). Fluctuations in water level cause E. cellulosa to produce shoots that are adapted to increased levels of water. The lack of correlation among parts of the shoot in the wet, as opposed to dry season results reflect the plasticity of the E. cellulosa shoot system in response to environmental parameters, such as water level, that override the innate developmental correlation, as found in the dry season data.

This study shows that $E$. cellulosa has a stereotyped sympodial growth pattern in erect shoots, producing 3 bracts with short internodes, then 1 bract with a long internode and terminating in an inflorescence. Reiteration occurs from a bud in the axil of the first bract (B1). Spread of plants comes from a bud axillary to B2, and this bud has a different growth pattern. It grows monopodially for some internodes, then becemes sympodial and forms an erect shoot. This horizontal shoot has a transitional region in which there may be changes in the location of internode expansion, accompanied by changes in response to gravity and in leaf structure. 
Although the growth of the VS system seems well-defined with respect to number and degree of expansion of nodes, growth of the HS system is less modular. Further studies are needed to investigate the plasticity of these shoot systems and the transition from monopodial to sympodial growth. Investigations into the physiological and/or environmental factors that trigger the switch from monopodial growth to sympodial growth would be interesting. Knowledge of the growth pattern of E. cellulosa provides a framework for studies of other species of Eleocharis in an effort to investigate differences in tufted vs. rhizomatous species of Eleocharis, as well as other sedges in the Everglades wet prairie community. 


\section{LITERATURE CITED}

BELL, A.D. 1991. Plant form: an illustrated guide to flowering plant morphology. Oxford University Press, New York, New York, USA.

BELL, A. D., and P. B. TOMLINSON. 1980. Adaptive architecture in rhizomatous plants. Botanical Journal of Linnean Society 80: 125-160.

BERLYN, G.P. and J.P. MIKSCHE. 1976. Botanical microtechnique and cytochemistry. The Iowa State University Press, Ames, Iowa, USA.

BRUHL, J.J. 1995. Sedge genera of the world: Relationships and a new classification of the cyperaceae. Australian Systematic Botany 8(2): 125-305.

BUSCH, J., MENDELSSOHN, I.A., LORENZEN, B. BRIX, H. and S.MIAO. 2004. Responses of Eleocharis cellulosa and Rhynchospora tracyi (Cyperaceae) from the wet prairies of the Florida Everglades to anthropogenic changes in hydrology and phosphate availability. Aquatic Botany 78: 37-54.

DAVIS, S.M. and J.C. OGDEN [eds.] 1994. Everglades: The Ecosystem and Its Restoration. St. Lucie Press. Delray Beach, Florida, USA.

EDWARDS, A.L., LEE, D.W. and J.H. RICHARDS. 2003. Responses to a fluctuating environment: Effects of water depth on growth and biomass allocation in Eleocharis cellulosa Torr. (Cyperaceae). Canadian Journal of Botany 81: 964975.

FISHER, J. B. 1973. Control of growth and development in the monocotyledons-new areas of experimental research. Quarterly Review of Biology 48: 291-298.

FISHER, J. B., and J. C. FRENCH. 1978. Internodal meristems of monocotyledons: Further studies and a general taxonomic survey. Annals of Botany 42: 41-50.

GODFREY, R.K. and J.W. WOOTEN. 1979. Aquatic and Wetland Plants of Southeastern United States. pp. 307-313. The University of Georgia Press, Athens, Georgia, USA.

GOETGHEBEUR, P. 1985. Studies in Cyperaceae 6. Nomenclature of the suprageneric taxa in the Cyperaceae. Taxon 34(4): 617-632.

MORA, L.E. 1960. Beiträge zur Entwicklungsgeschichte und vergleichenden Morphologie der Cyperaceen. Beiträge zur Biologie der Pflanzen 35: 277. 
PHILLIPS, M. 1953. Studies in the quantitative morphology and ecology of Eriophorum angustifolium Roth: I. Horizontal shoot System. Journal of Ecology 41(2): 295318.

ROUTLEDGE, R.D. 1987. Horizontal shoot architecture for dispersal in EleocharisPalustris. Canadian Journal of Botany 65 (6): 1218-1223.

STEVENS, K.L. and G.B. MERRILL. 1980. Growth inhibitors from spikerush Eleocharis-Spp. Journal of Agricultural and Food Chemistry 28 (3): 44-646.

STOBER, Q. J., K. THORNTON, R. JONES, J. RICHARDS, C. IVEY, R. WELCH, M. MADDEN, J. TREXLER, E. GAISER, D. SCHEIDT, and S. RATHBUN. 2001. South Florida Ecosystem Assessment: Phase I/II--Everglades stressor interactions: Hydropatterns, eutrophication, habitat alteration and mercury contamination (Summary). EPA 904-R-01-002, United States Environmental Protection Agency, Region 4 Science and Ecosystem Support Division, Water Management Division and Office of Research and Development, Athens, Georgia, USA. 63 pp.

TOBE, J.D., BURKS, K.C., and R.W. CANTRELL. 1998. Florida wetland plants: An identification manual. pp. 65-67. University of Florida Press, Gainesville, Florida, USA.

TOMLINSON, P. B. 1973. Branching in monocotyledons. Quarterly Review of Biology 48: 458-466.

TUCKER, G.C. 1987. The genera of Cyperaceae in the southeastern United States. Journal of the Arnold Arboretum 68 (4): 361-445.

WALTERS, S.M. 1950. On the vegetative morphology of Eleocharis R. Br. New Phytologist 49(1): 1-7. 
Table 1.1. Summary of statistics for October 2003 (wet season) and April 2004 (dry season). Measurements are in $\mathrm{mm}$.

$$
\text { N } \quad \text { Mean } \pm \text { S.D. }{ }^{1} \quad \text { Range } \quad \text { Sig. }^{2}
$$

Culm Length (mm)

$\begin{array}{lllll}\text { Oct. } & 52 & 514 \pm 83 & 300-642 & <0.00 \\ \text { Apr. } & 84 & 259 \pm 54 & 155-393 & \end{array}$

Culm Diameter (mm)

$\begin{array}{ccccc}\text { Oct. } & 52 & 1.6 \pm 0.3 & 1.06-2.38 & <0.00 \\ \text { Apr. } & 84 & 1.3 \pm 0.2 & 1-1.76 & \end{array}$

Bract 2 Length (mm)

$\begin{array}{llccc}\text { Oct. } & 37 & 60 \pm 29 & 28-159 & <0.00 \\ \text { Apr. } & 56 & 35 \pm 9 & 15-60 & \end{array}$

Bract 3 Length (mm)

$\begin{array}{lllll}\text { Oct. } & 37 & 178 \pm 39 & 97-260 & <0.00 \\ \text { Apr. } & 56 & 79 \pm 20 & 53-133 & \end{array}$

HS Length (mm)

$\begin{array}{llccc}\text { Oct. } & 30 & 142 \pm 70 & 9-312 & <0.00 \\ \text { Apr. } & 30 & 98 \pm 43 & 37-184 & \end{array}$

HS Internode Number

$\begin{array}{lllll}\text { Oct. } & 30 & 6 \pm 1 & 3-8 & <0.00^{3} \\ \text { Apr. } & 30 & 5 \pm 1 & 3-7 & \end{array}$

${ }^{1}$ Average \pm standard deviation

${ }^{2}$ Significance in 1-way ANOVA tests on seasonal effects; $\mathrm{N}=60, \mathrm{df}=1$

${ }^{3}$ Kruskall-Wallis significance test 
Fig.1.1. A. Model for growth of Heleocharis (=Eleocharis) acicularis redrawn from Mora (1960). Determinate sympodial units develop from axillary buds. Different line shading indicates individual units. Indeterminate growth $=\rightarrow$; determinate growth $=\bullet$. B. Model for growth of Eleocharis palustris from Walters 1950. The horizontal shoot of E. palustris bears three leaf sheaths, $\mathrm{X} 1, \mathrm{X} 2$ and $\mathrm{X} 3$. Only the lower, $\mathrm{X} 1$, sheath bears an axillary bud, that develops into a new shoot. Roman numerals indicate successive sympodial units.

A.

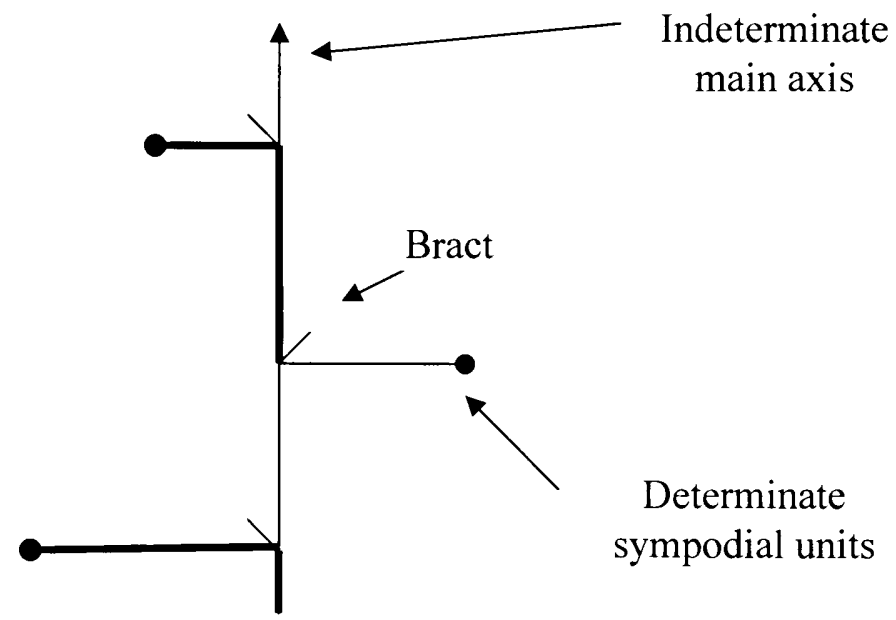

B.

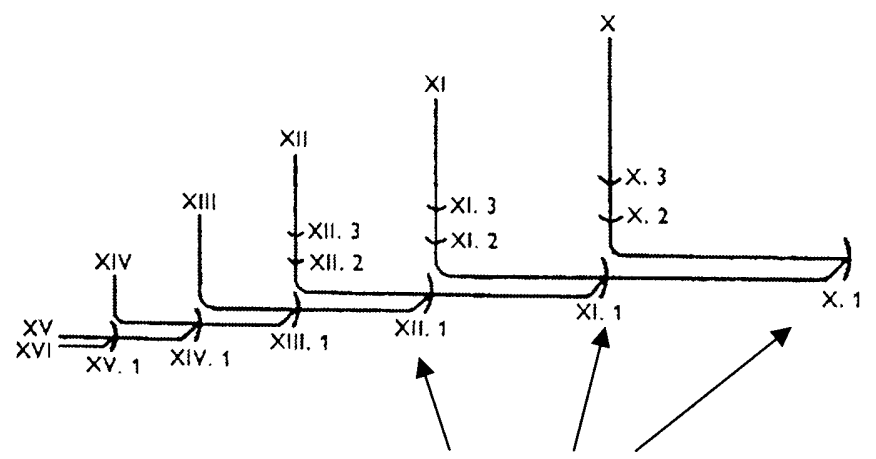

Nodes 
Figure 1.2. Patterns of growth for Eleocharis cellulosa. A. Monopodial growth. Dashed lines indicate units that have branched off of main shoot axis. B. Sympodial growth. Various patterns of dashed lines indicate individual units that have branched off of previous unit. Indeterminate growth $=\rightarrow$; Determinate growth $=\bullet$.

A.

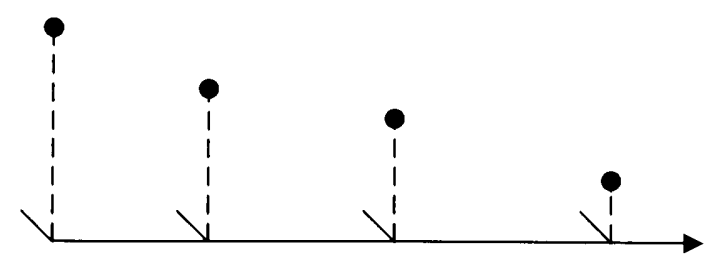

Direction of growth

B.

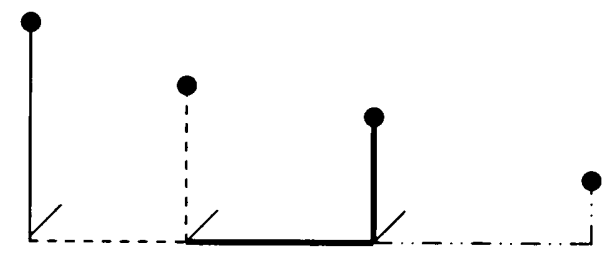

Direction of growth 
Figure 1.3. A. Shoot system of E. cellulosa showing its vertical shoots (VS), culms and horizontal shoots (HS). B. Close up of young shoot of E. cellulosa from A. showing its roots (R). Black arrow marks a HS tip (T) that is beginning to turn up. Asterisks mark nodes along the HS; not all internodes are marked. Scale in inches.

A.

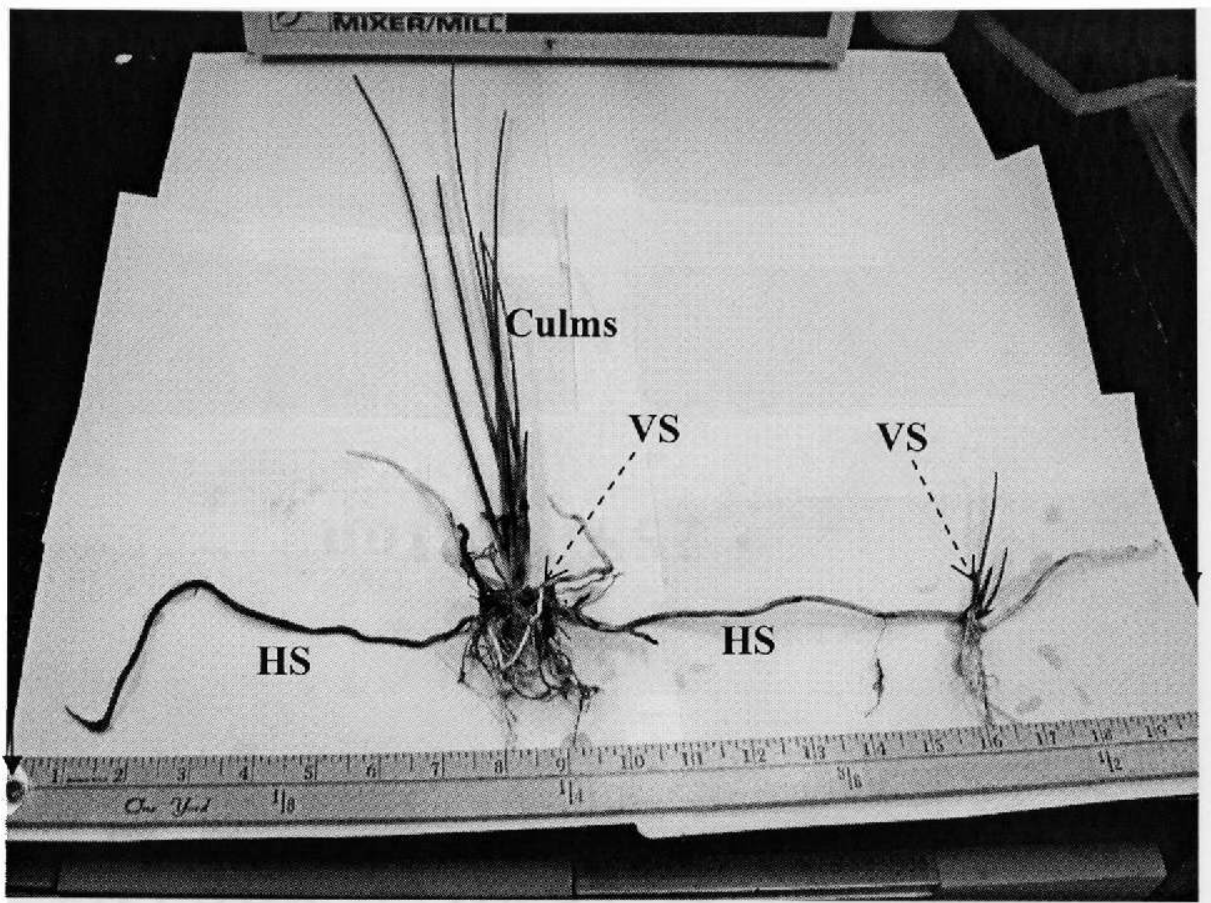

B.

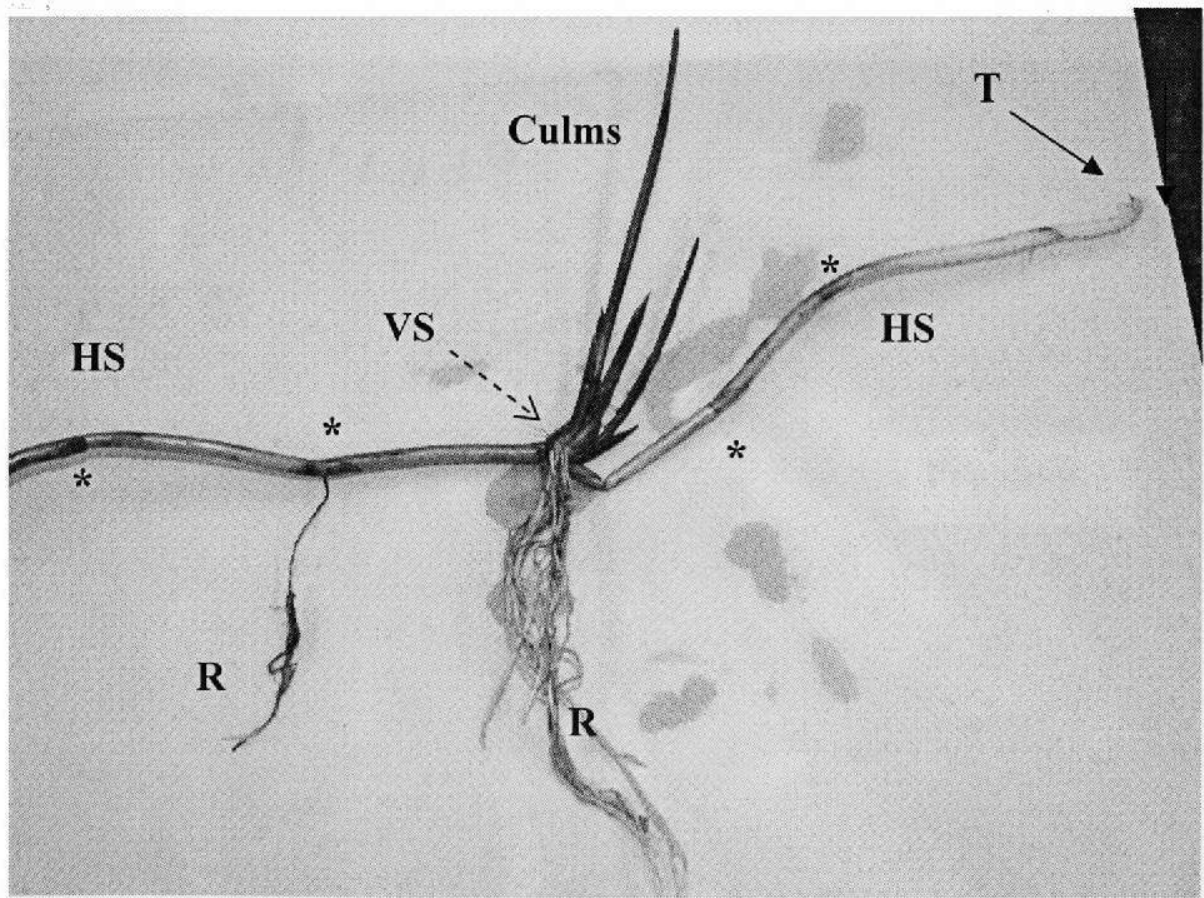


Figure 1.4. A. HS to VS transition. Successively produced internodes are shorter and thicker as the shoot becomes erect. $\mathrm{B}=$ bracts; asterisks mark nodes. B. Base of VS bearing upright culms showing prophyll on HS emerging from VS through the base of the $\mathrm{B} 2$ bract. $\mathrm{C}=$ culm; Short white arrow $=$ underdeveloped culm.

A.

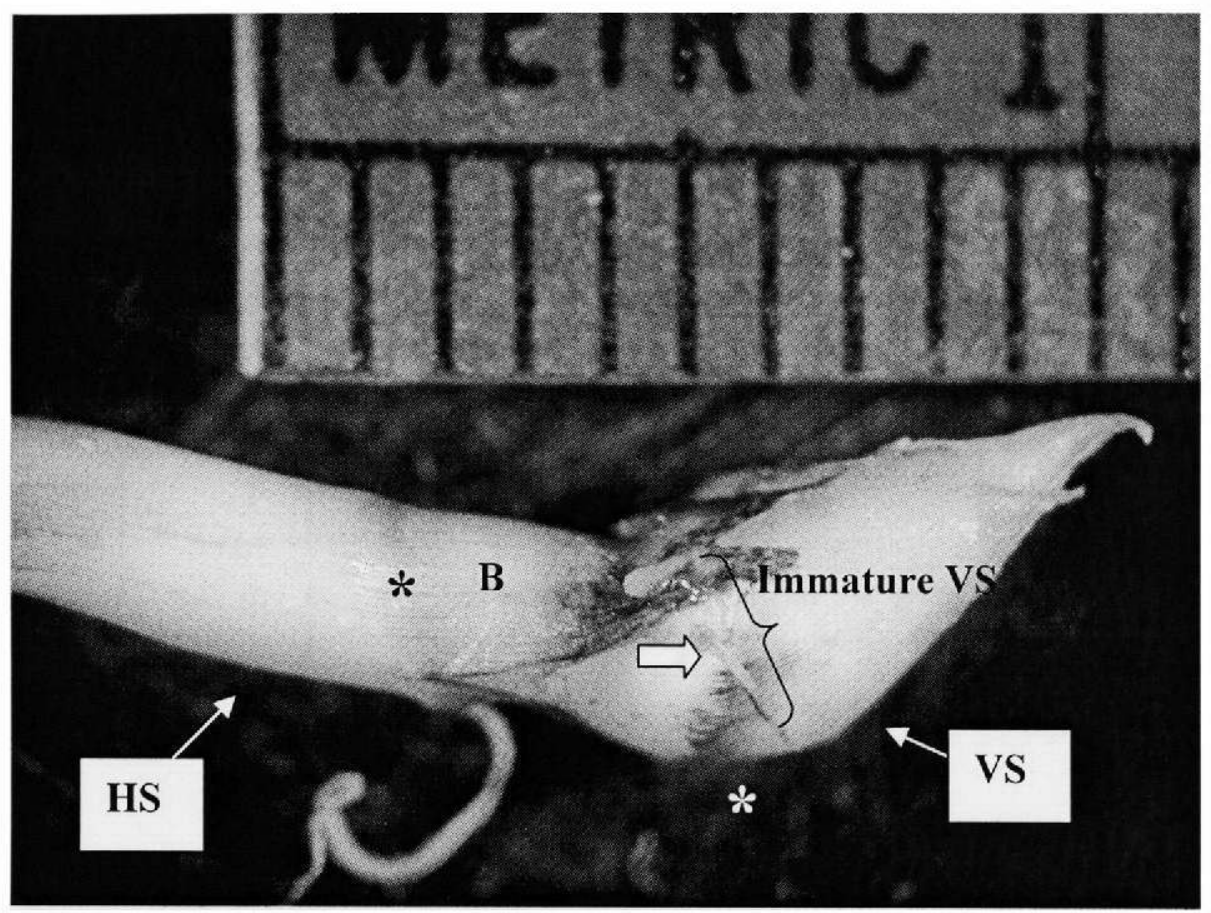

B.

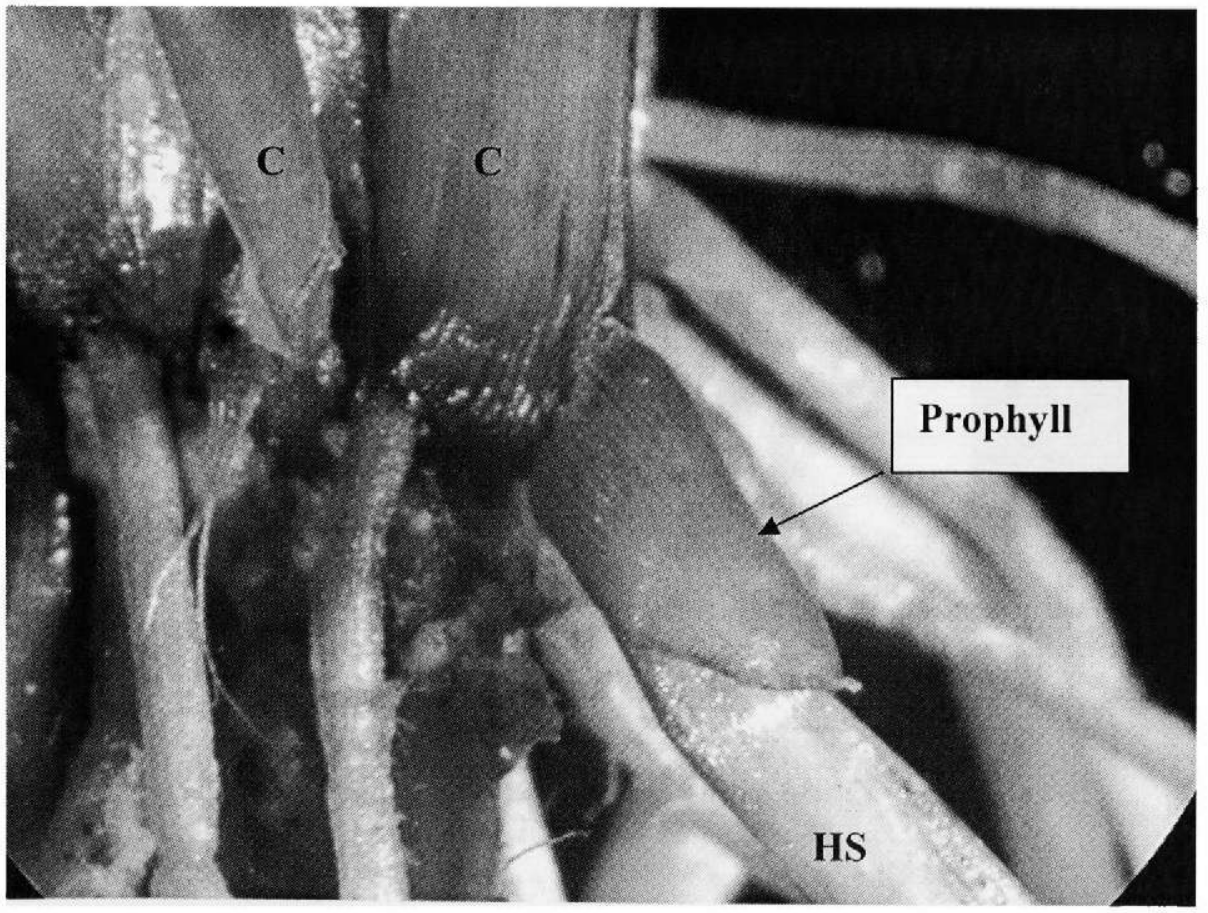


Figure 1.5. Average internode length for the first internode (1), middle internode (2) and final internode (3) for October 2003 (A) and April 2004 (B). Internode number 1 is the first internode before the prophyll at the beginning of the horizontal shoot. Error bars $= \pm$ 1 standard error.

A.

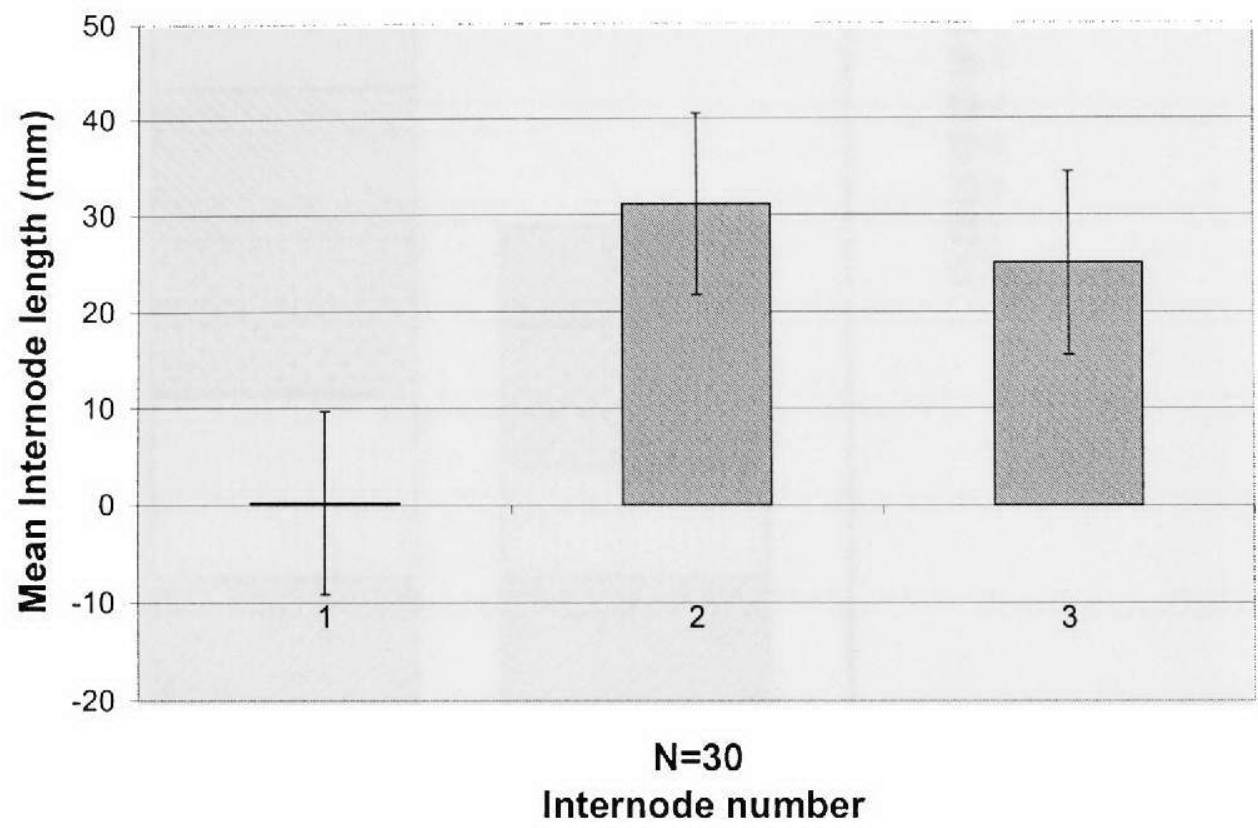

B.

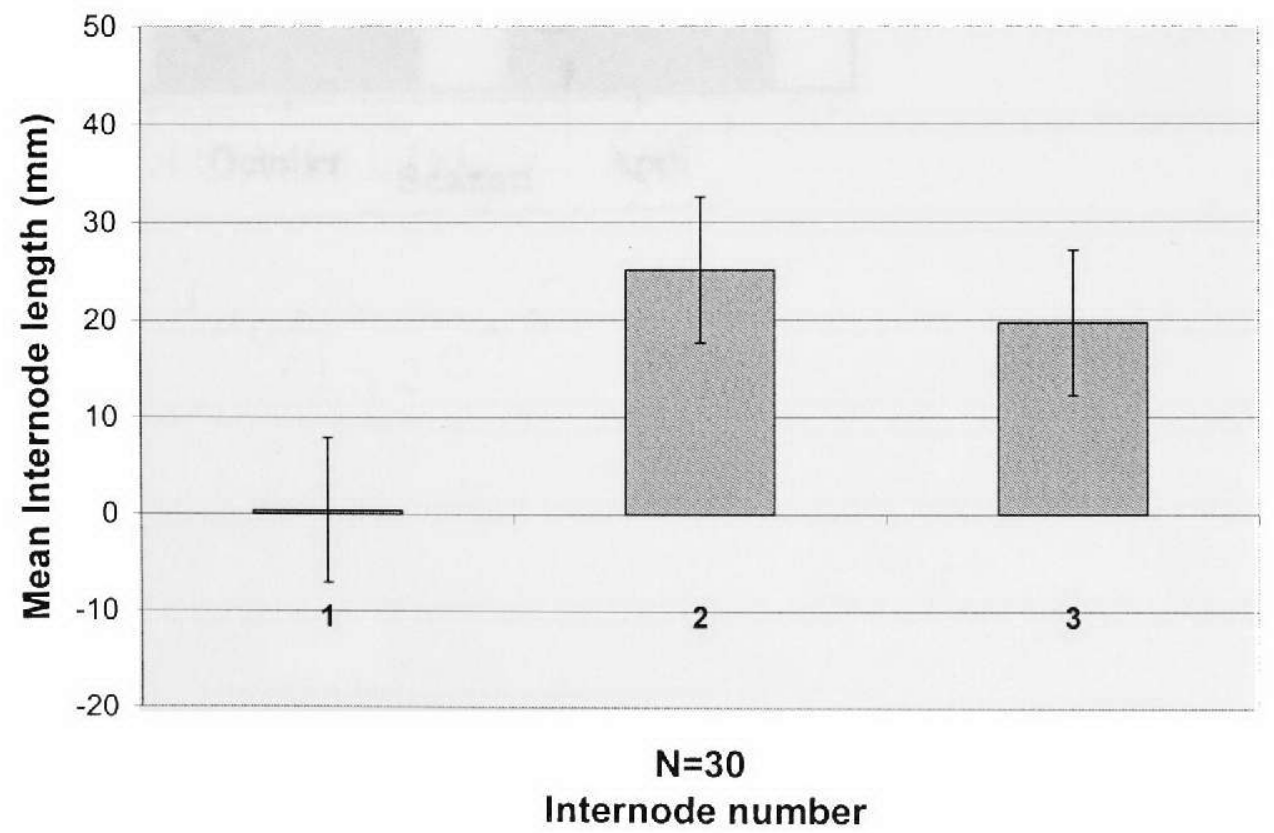


Figure 1.6. Average internode length of successive HS internodes of E. cellulosa for the wet (October 2003) and dry (April 2004) seasons. $N=30$. Internodes numbered from the base of the HS; first internode is after prophyll internode.

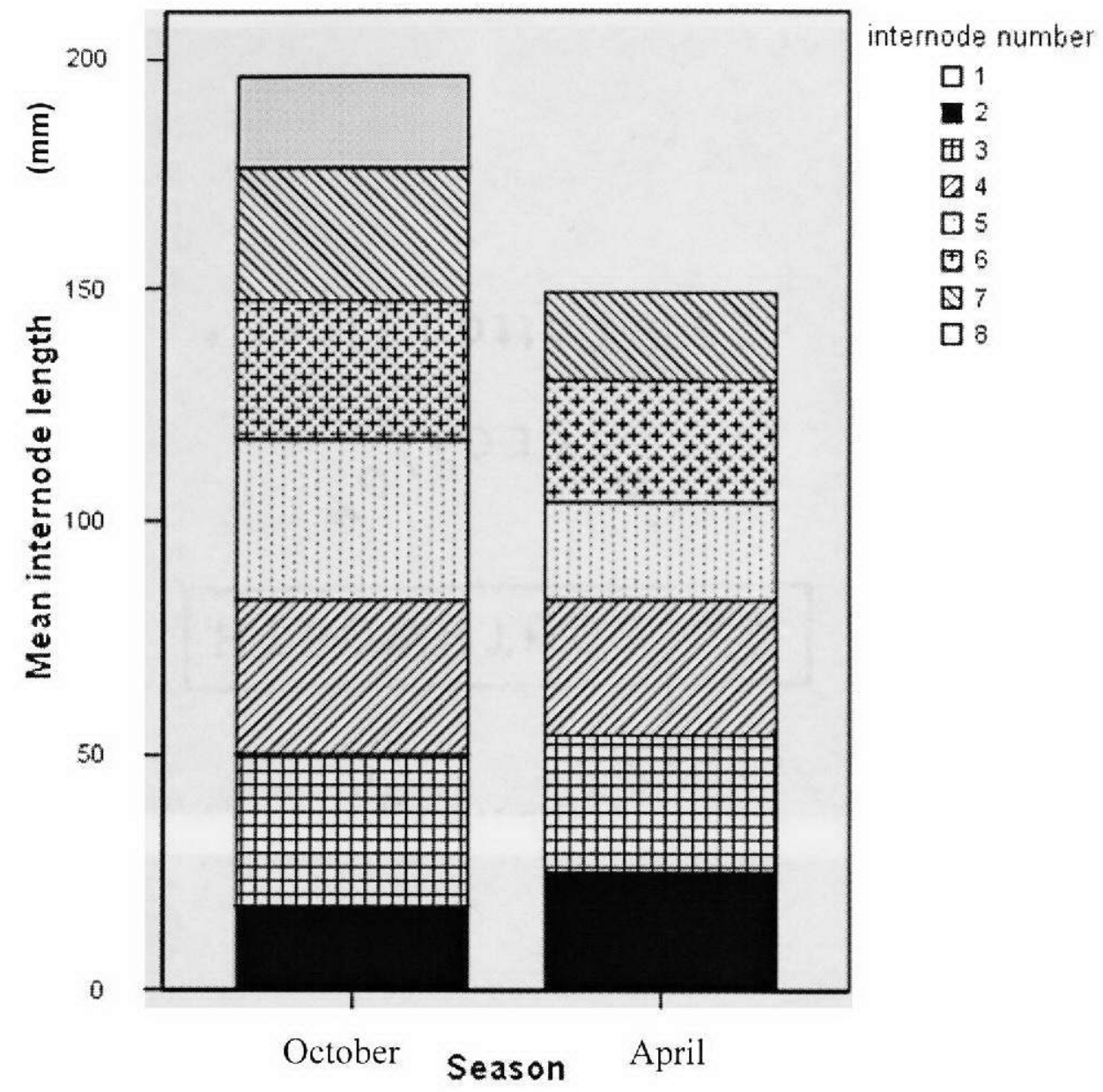


Figure 1.7. A. Immature E. cellulosa culm showing hyaline B2 and B3. These bracts enclosed the young culm. B. Mature E. cellulosa culm showing B4 which ensheaths the shoot tip; the hole is formed by the top of this sheath. C. Section of the tip of a mature culm showing an aborted inflorescence inside. D. Mature inflorescence.

A.

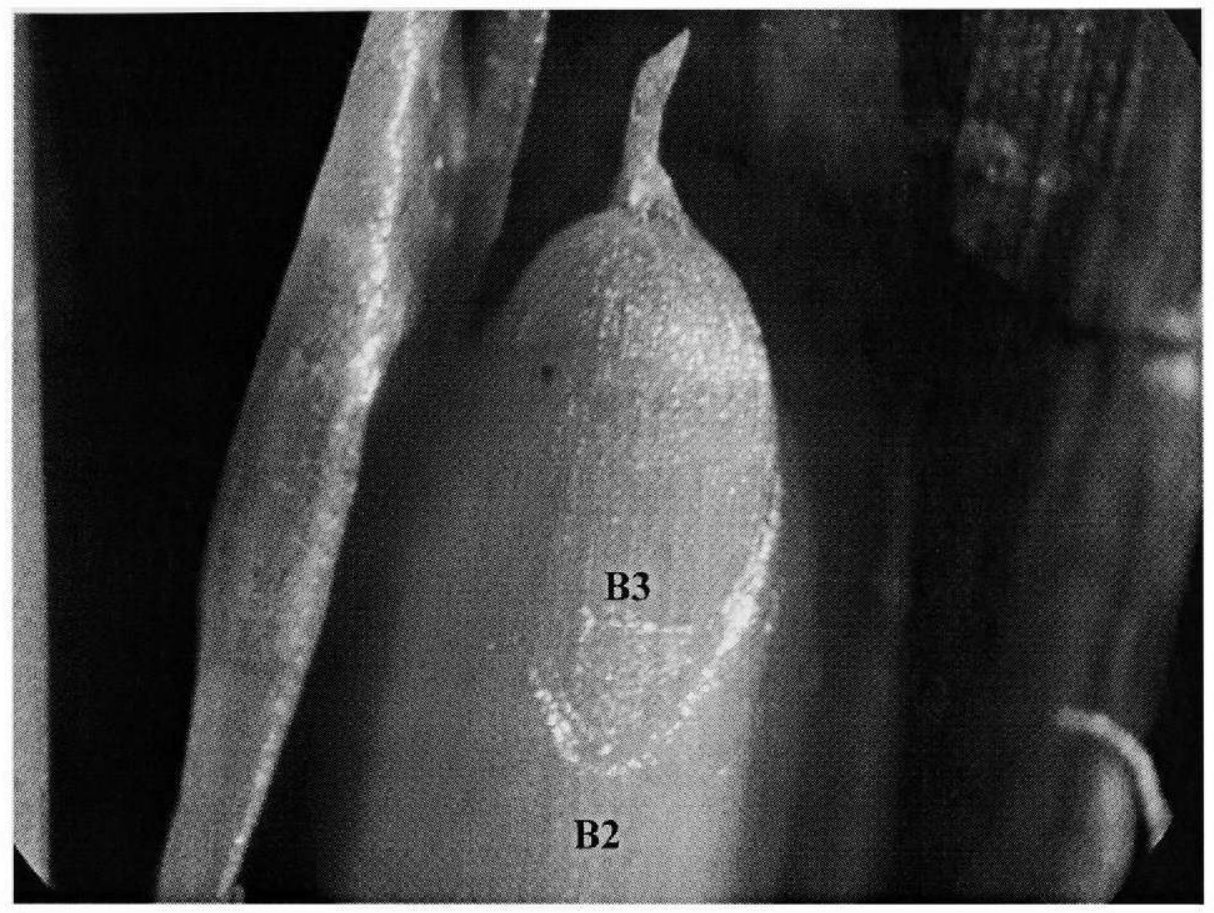

B.

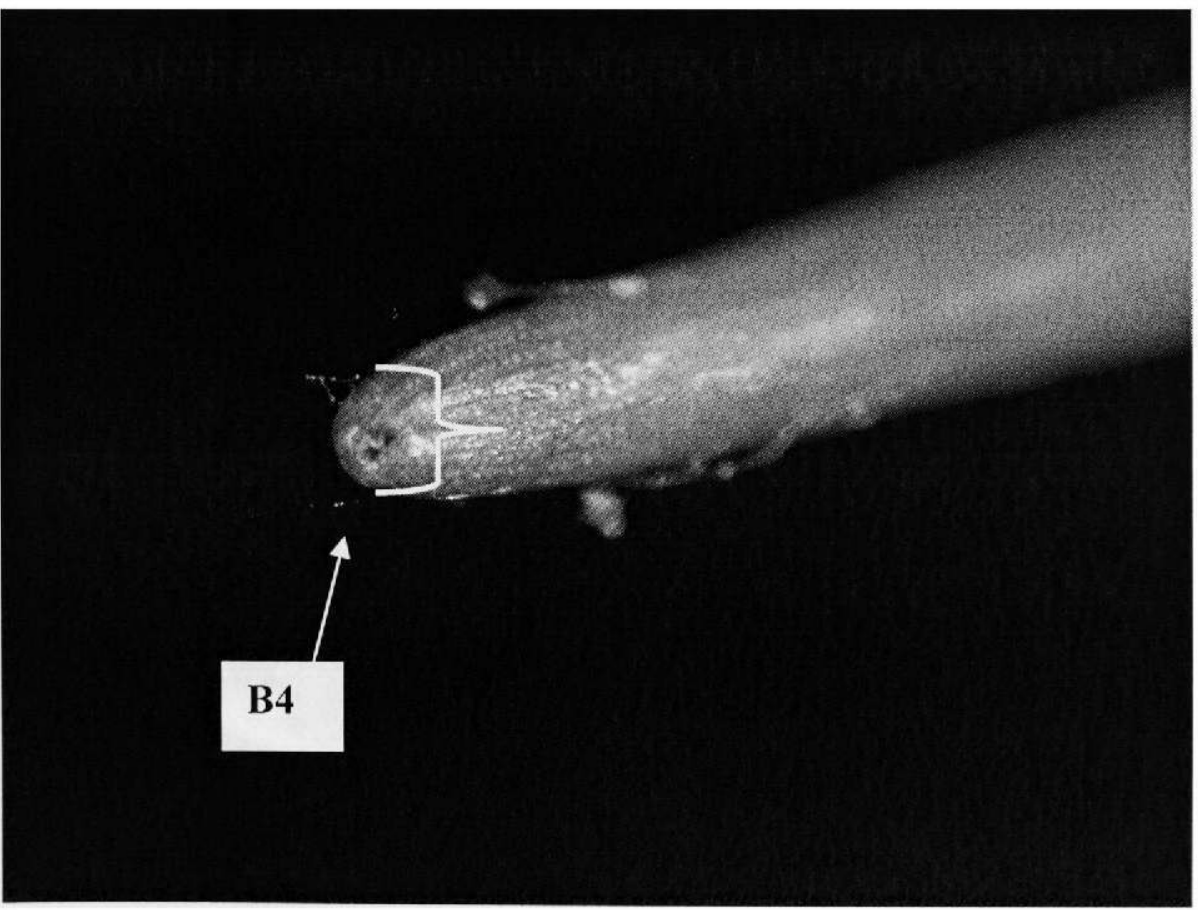


C.

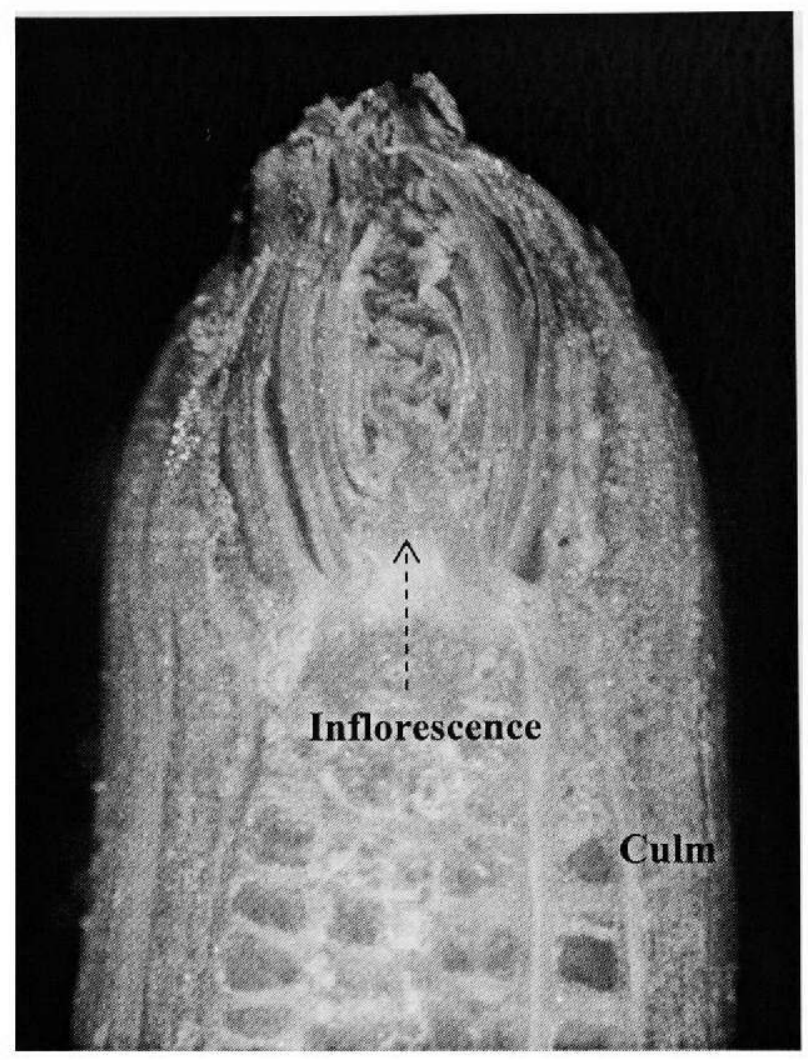

D.

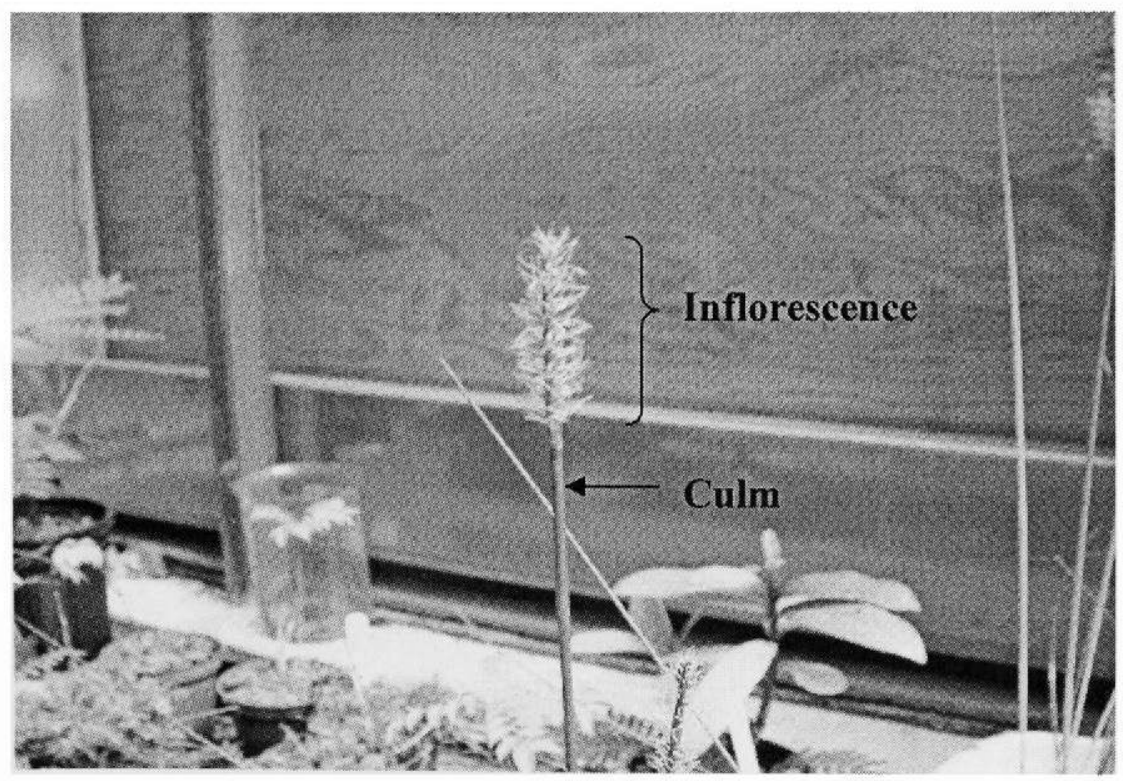


Figure 1.8. Cross section of a E. cellulosa VS. A is unlabeled, $\mathrm{B}$ is labeled. $\mathrm{S}=$ sympodium; $\mathrm{B}$ = bract; numbers refer to sympodium number; $\mathrm{B} 1$ is the prophyll on the axillary bud that forms the sympodium; B2 and B3 are the second and third bracts; circles enclose a sympodial unit $=$ the B1 axillary bud.

A.

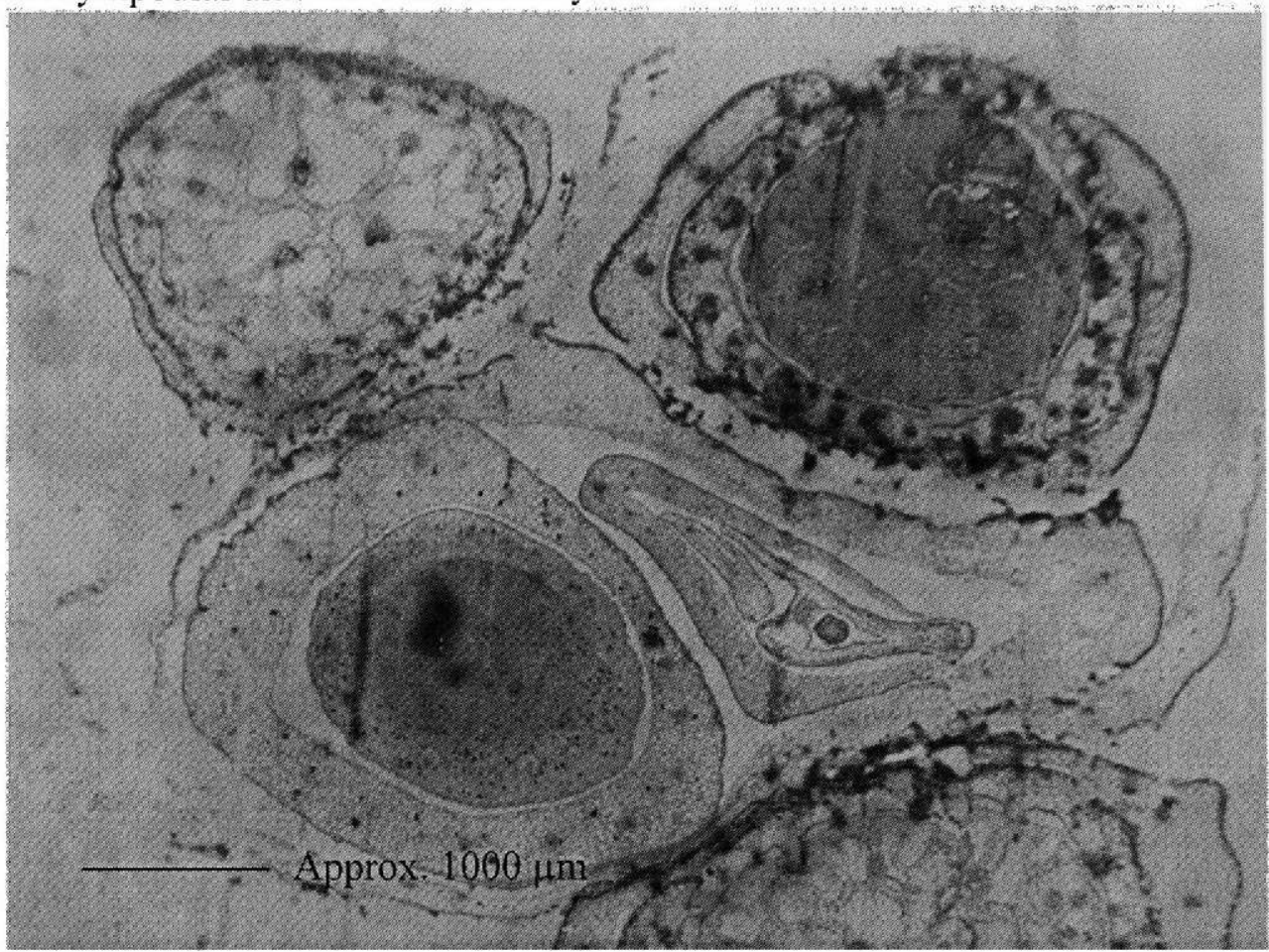

B.

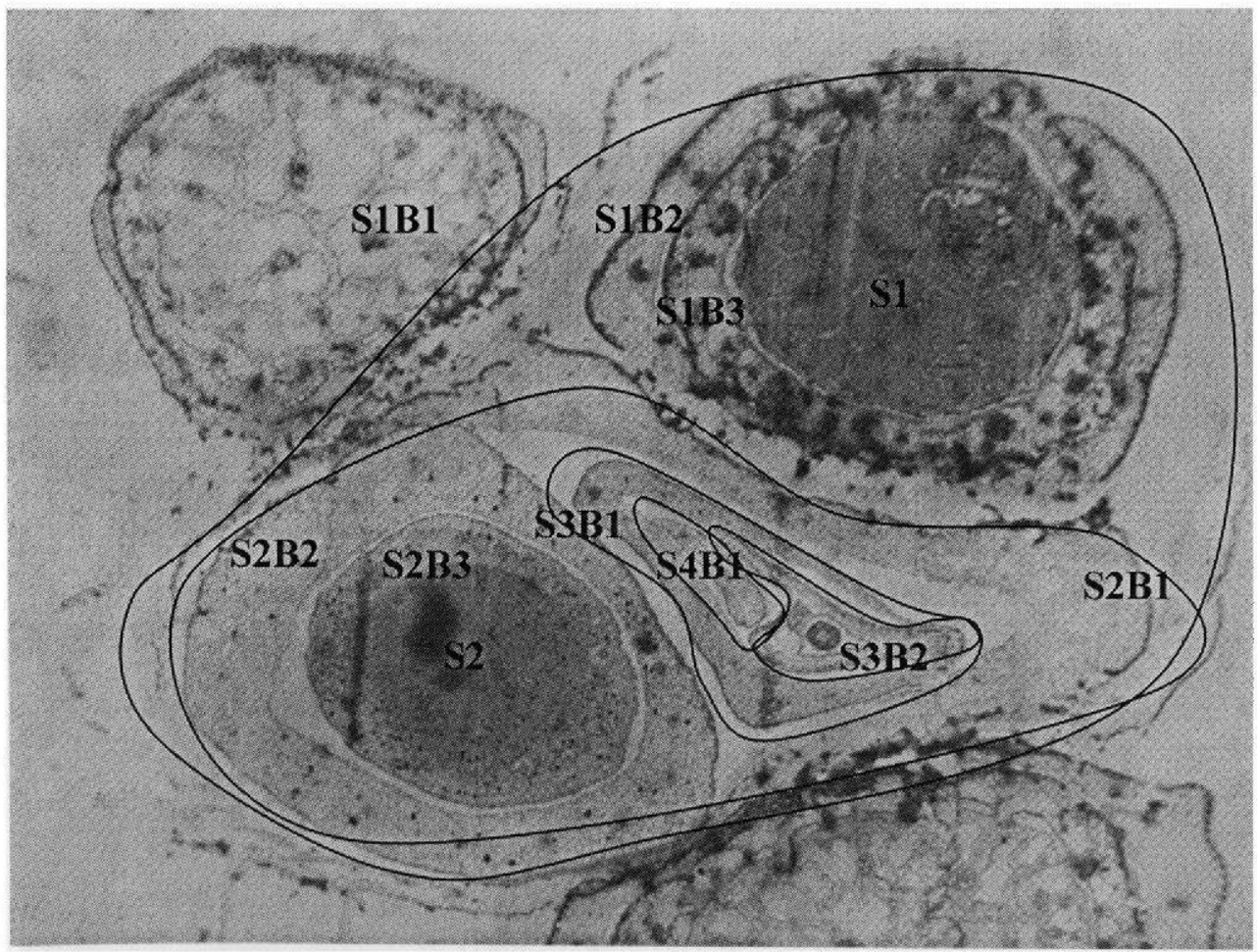


Figure 1.9. SEM of four developing sympodia at different stages on a VS shoot. A is unlabeled, B is labeled. Initially, the culm and axillary bud are both surrounded by a leaf, bract 1 . As the culm and axillary bud mature, additional individual bracts that surround them can be seen. Abbreviations as in Fig. 1.7.

A.

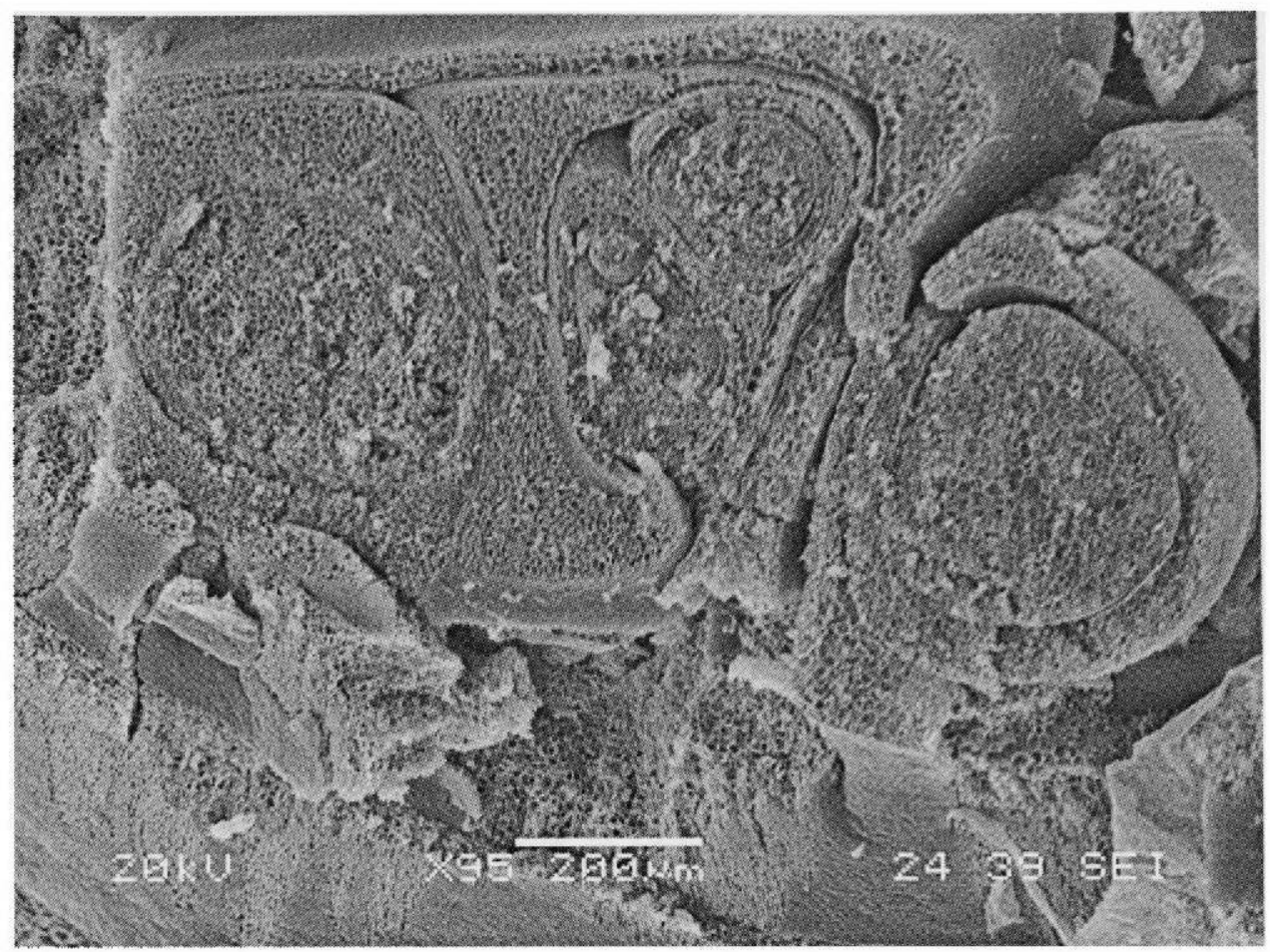

B.

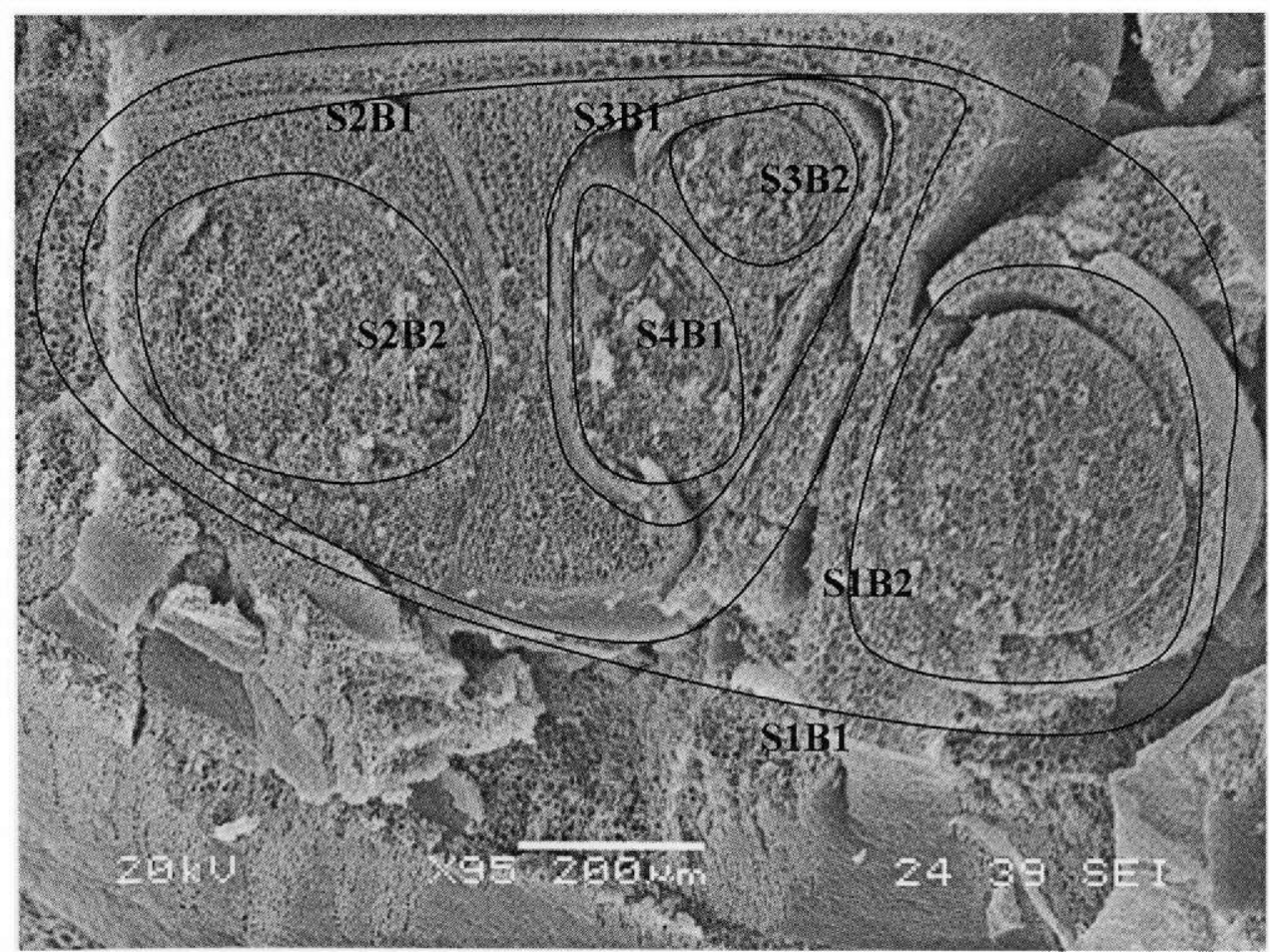


Figure 1.10. Individual culm next to an axillary bud. A is unlabeled, B is labeled. Bracts, $\mathrm{B} 2$ and B3, closely surround the culm. Abbreviations as in Fig. 1.7.

A.

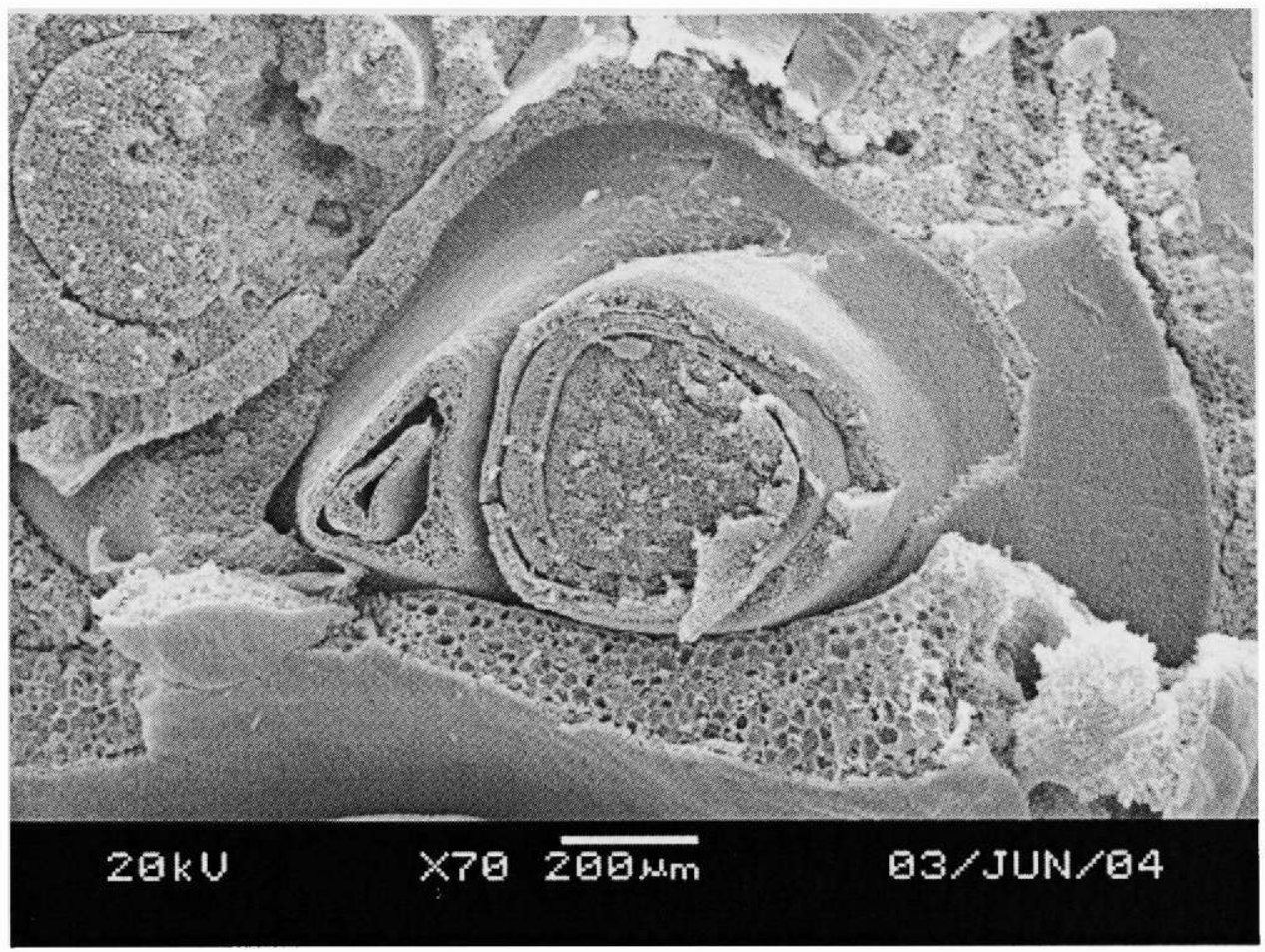

B.

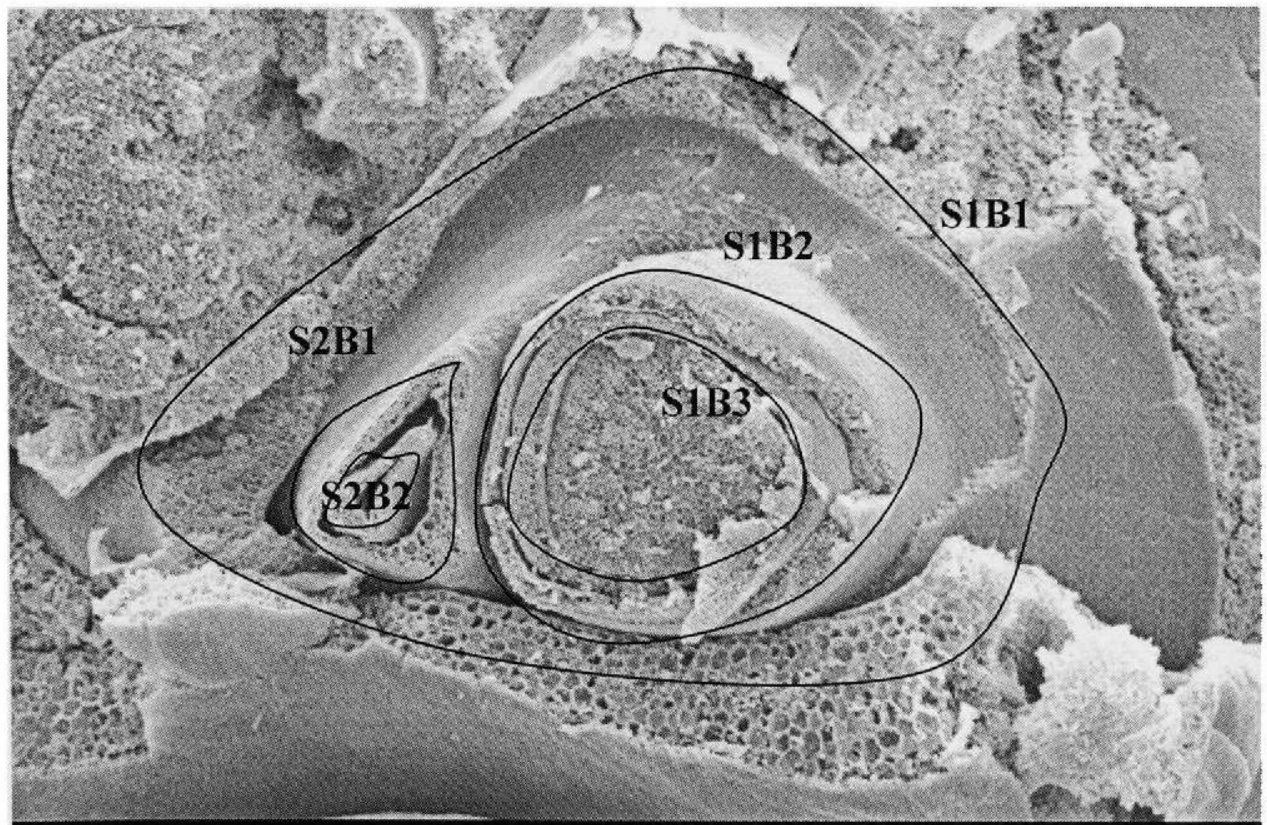


Figure 1.11. Cross-section of a horizontal shoot soon after it started to grow vertically. A is unlabeled, B is labeled. The numbers depict the age of the sympodia with 1 being the oldest. Abbreviations as in Fig. 1.7.

A.

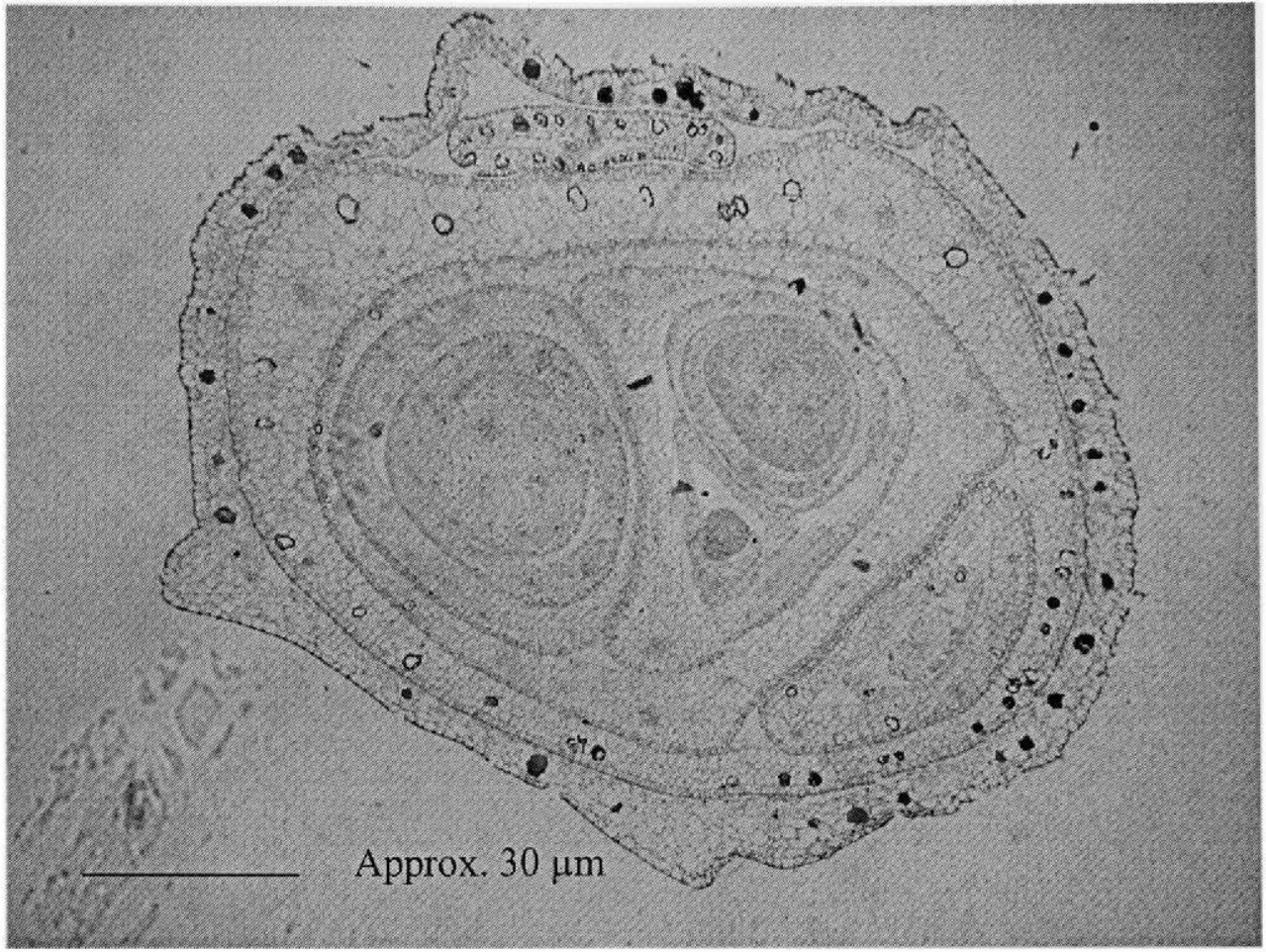

B.

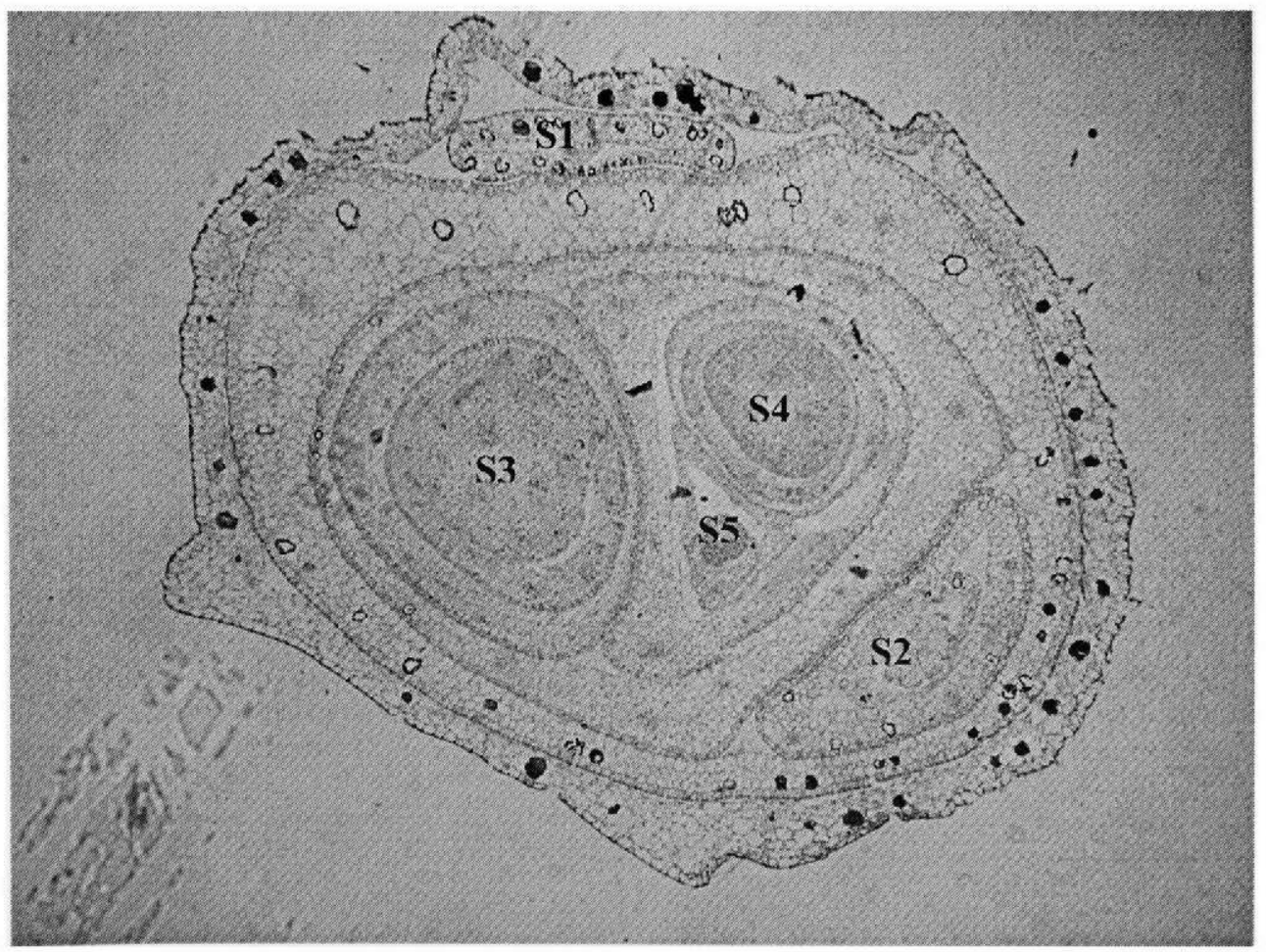


Figure 1.12. Cross-section of a horizontal shoot, prior to turning up. A is unlabeled, B is labeled. The numbers depict the relative age of each sympodium with 1 being the oldest. Abbreviations as in Fig. 1.7.

A.

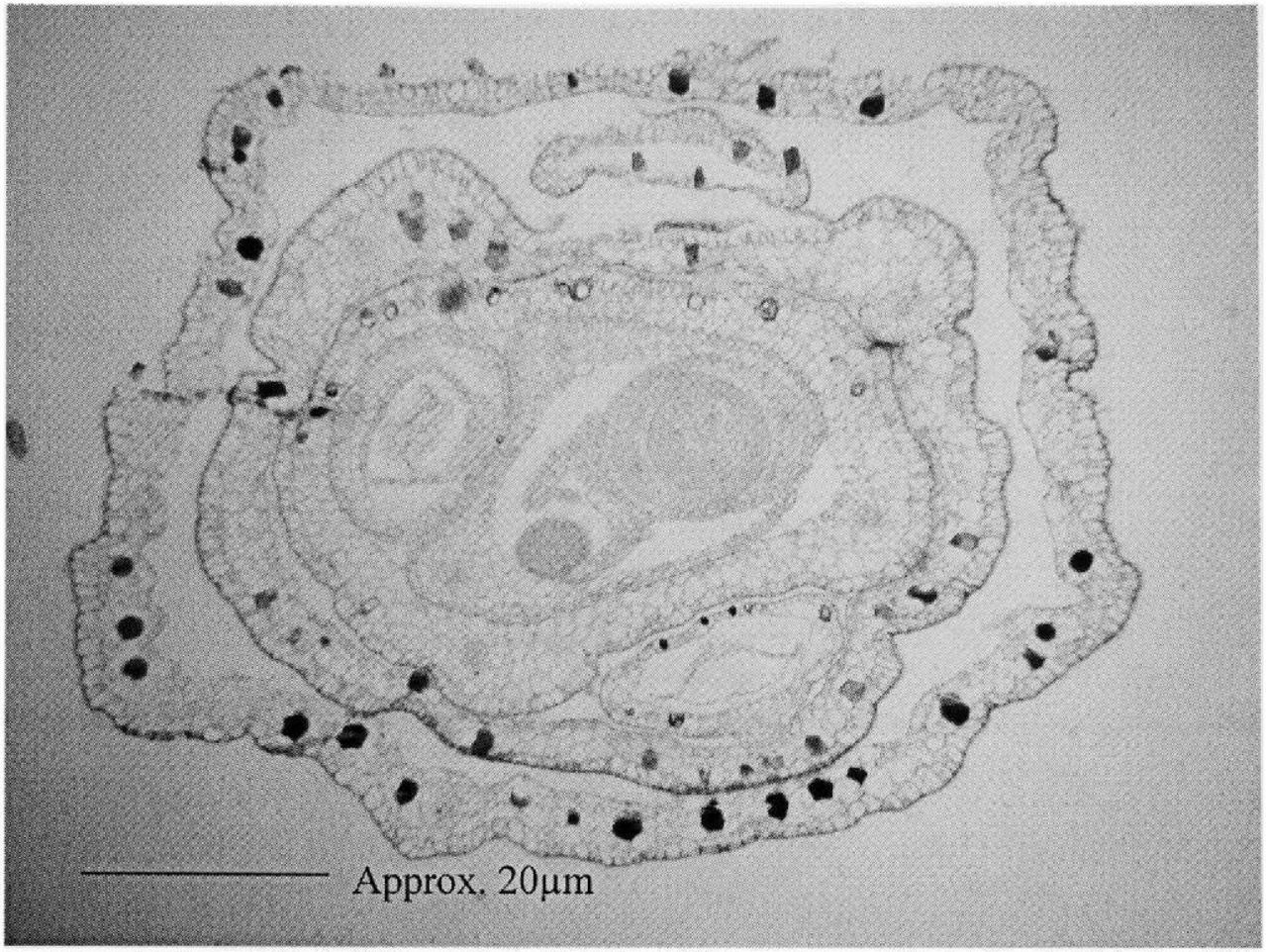

B.

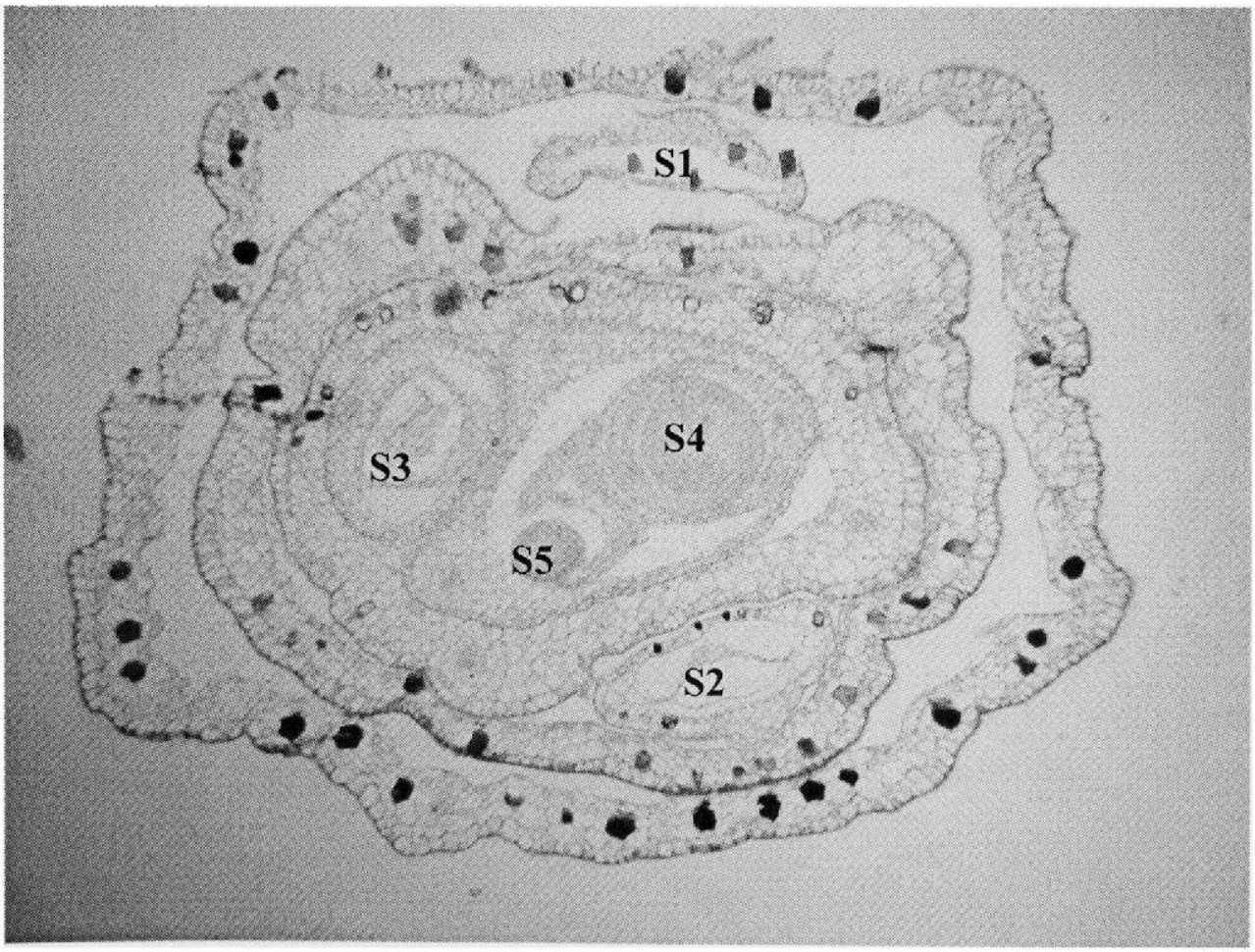


Figure 1.13. Close up of sympodium from Fig. 1. A is unlabeled, B is labeled. The numbers depict the relative age of each sympodium with 1 being the oldest. Abbreviations as in Fig. 1.7.

A.

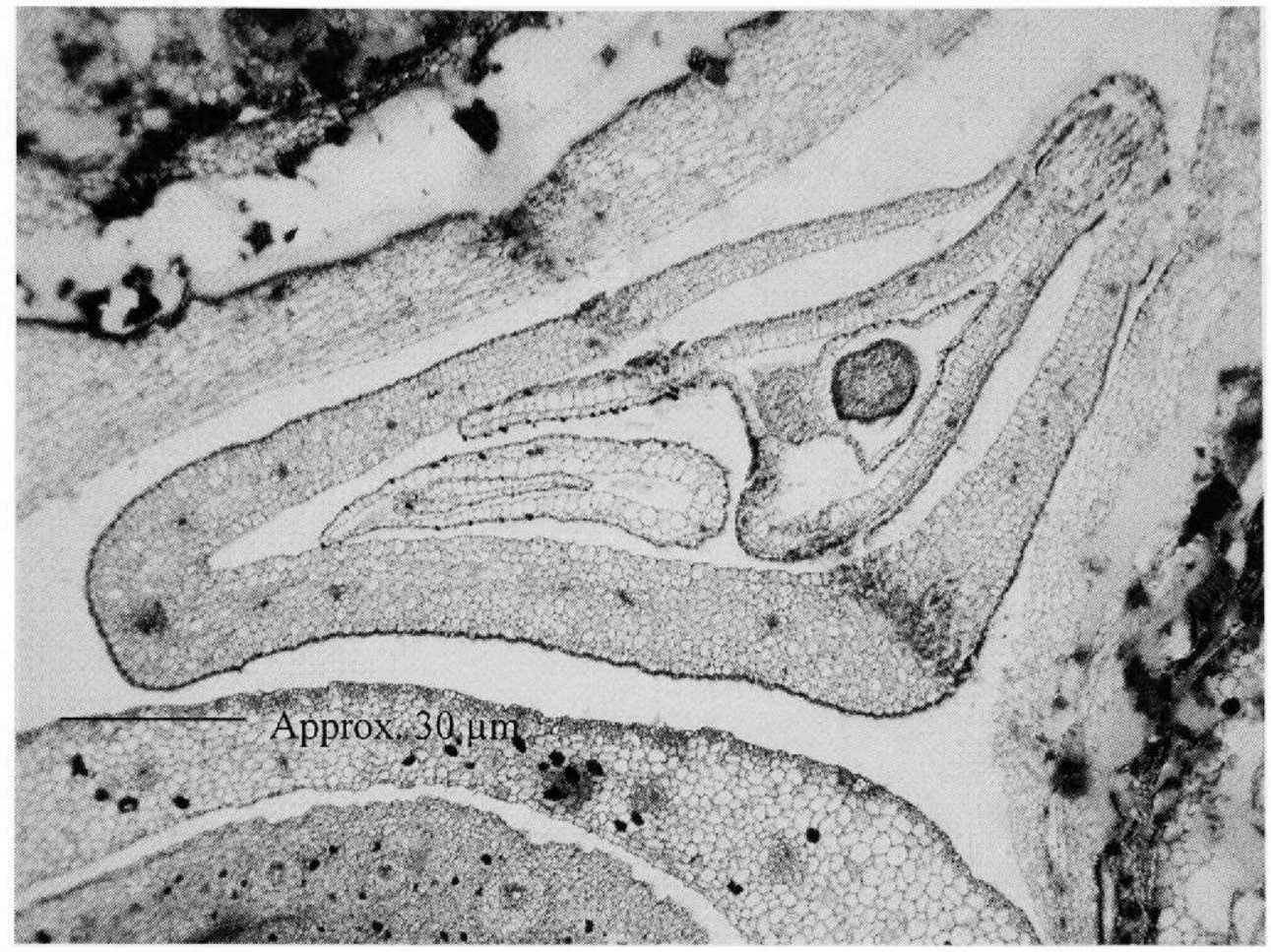

B.

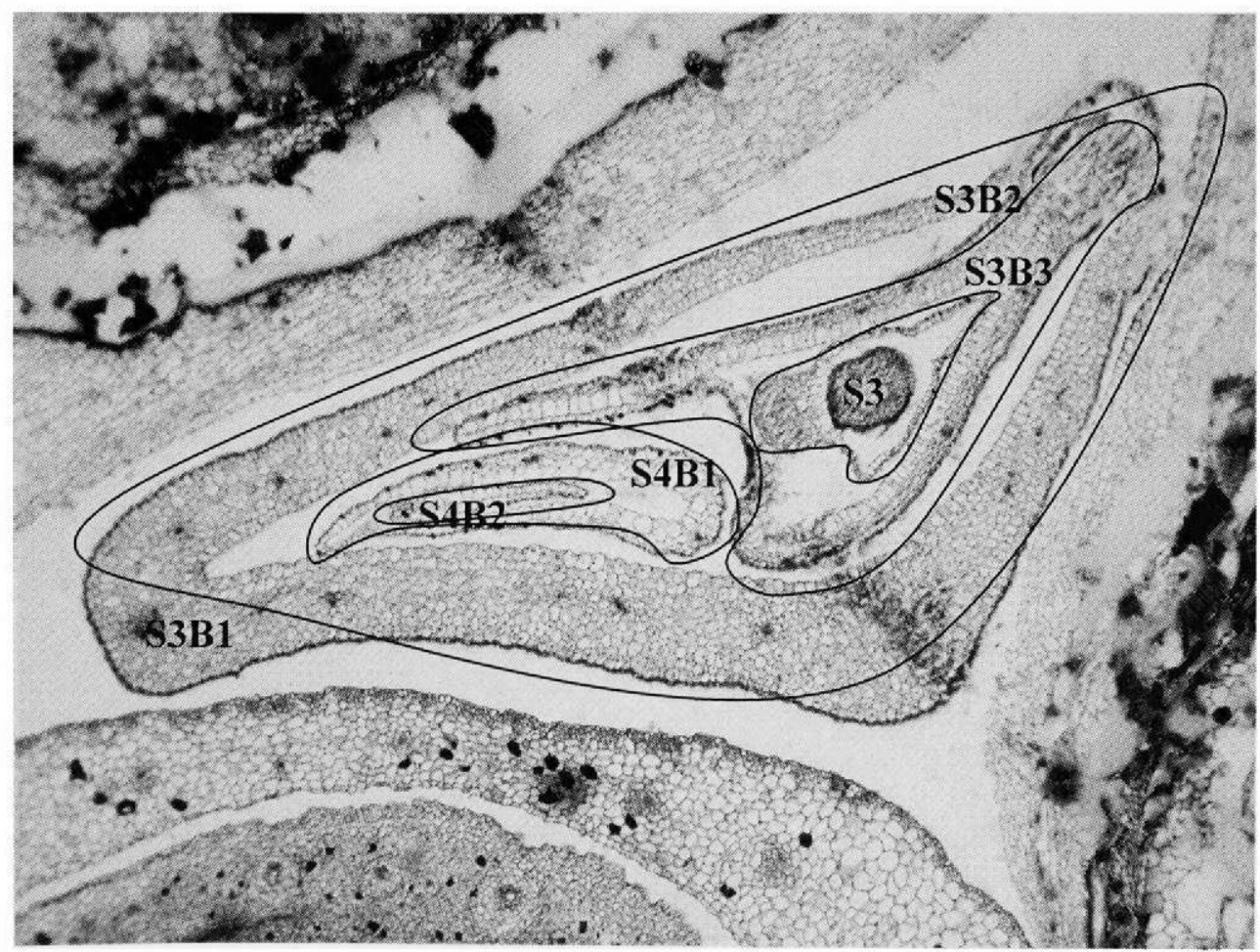


Figure 1.14. Cross section of a bud in the axil of B2 on S3. A is unlabeled, B is labeled. Abbreviations as in Fig. 1.7.

A.

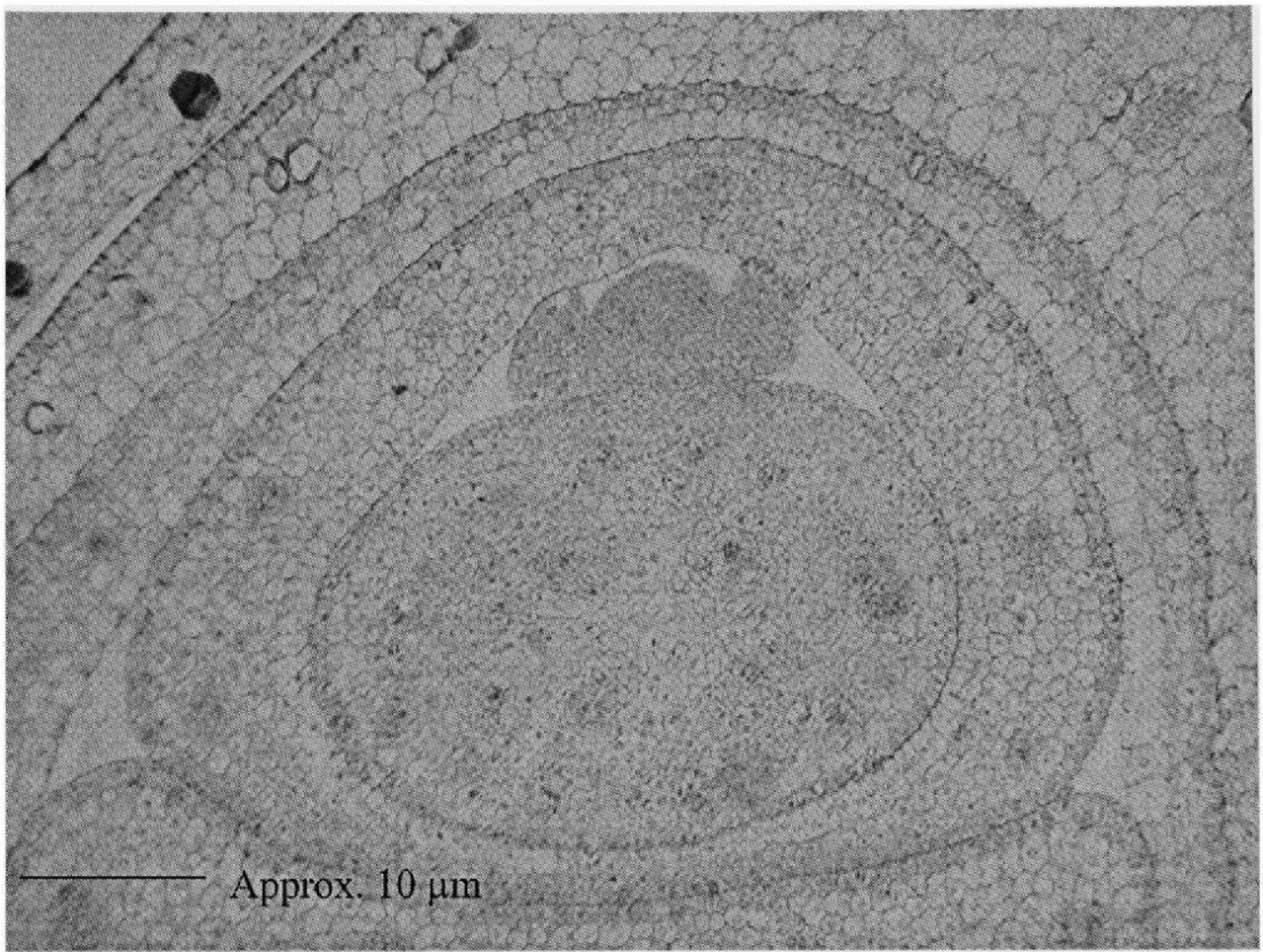

B.

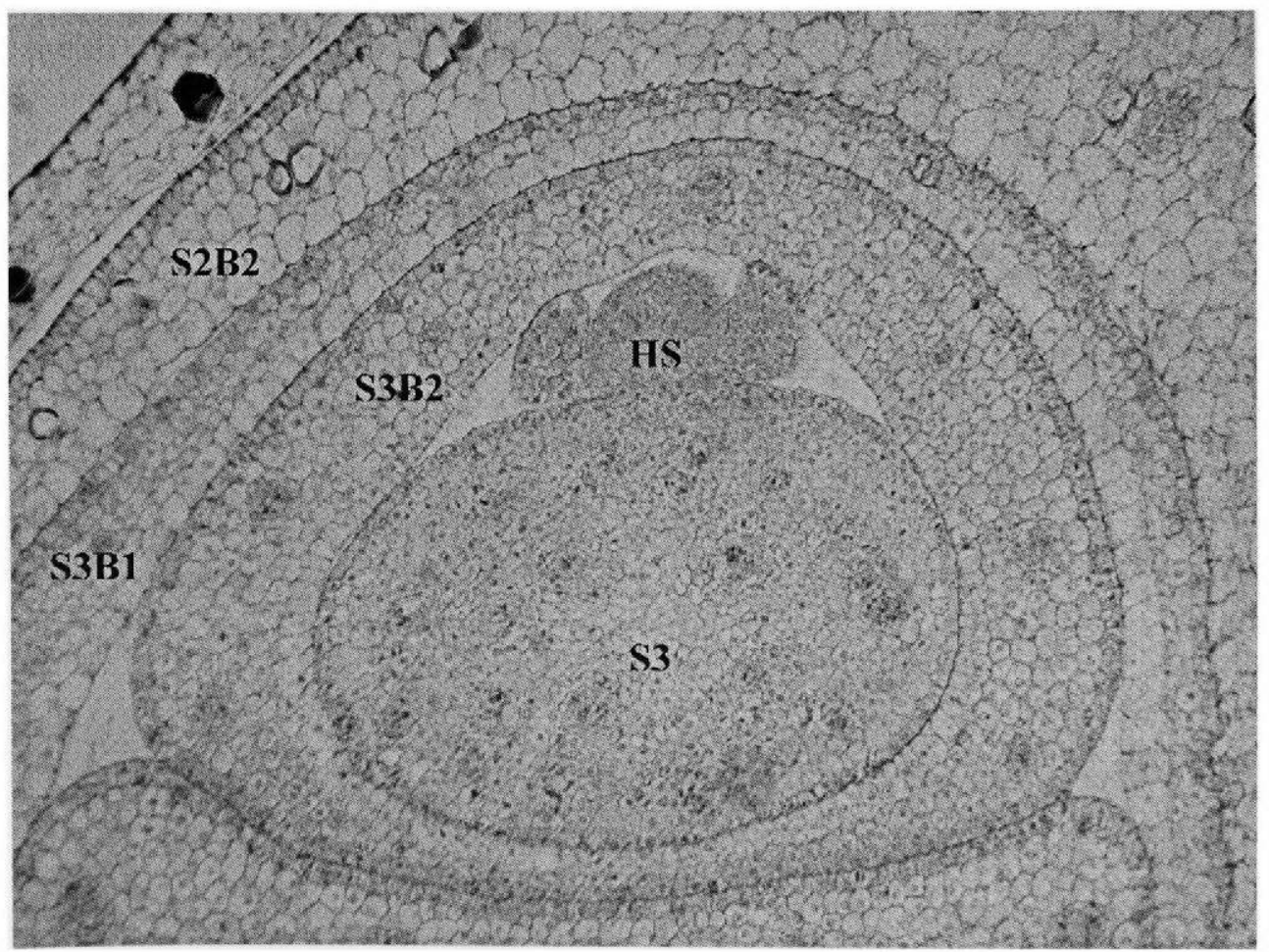


Figure 1.15. Cross-section of a bud from B2. A is unlabeled, B is labeled. The numbers depict the ages of the bracts with 1 being the oldest bract. $\mathrm{B}=$ bract A.

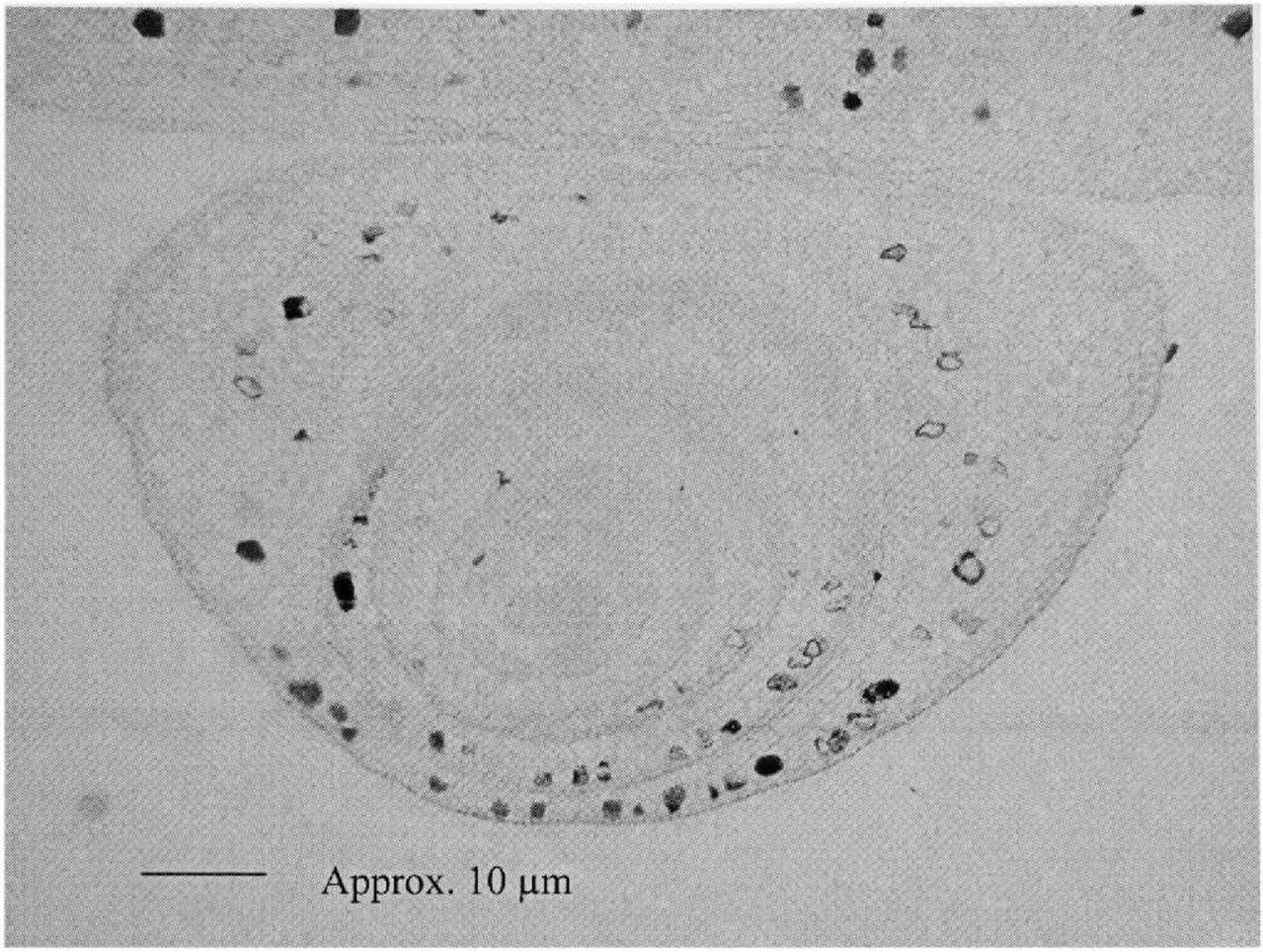

B.

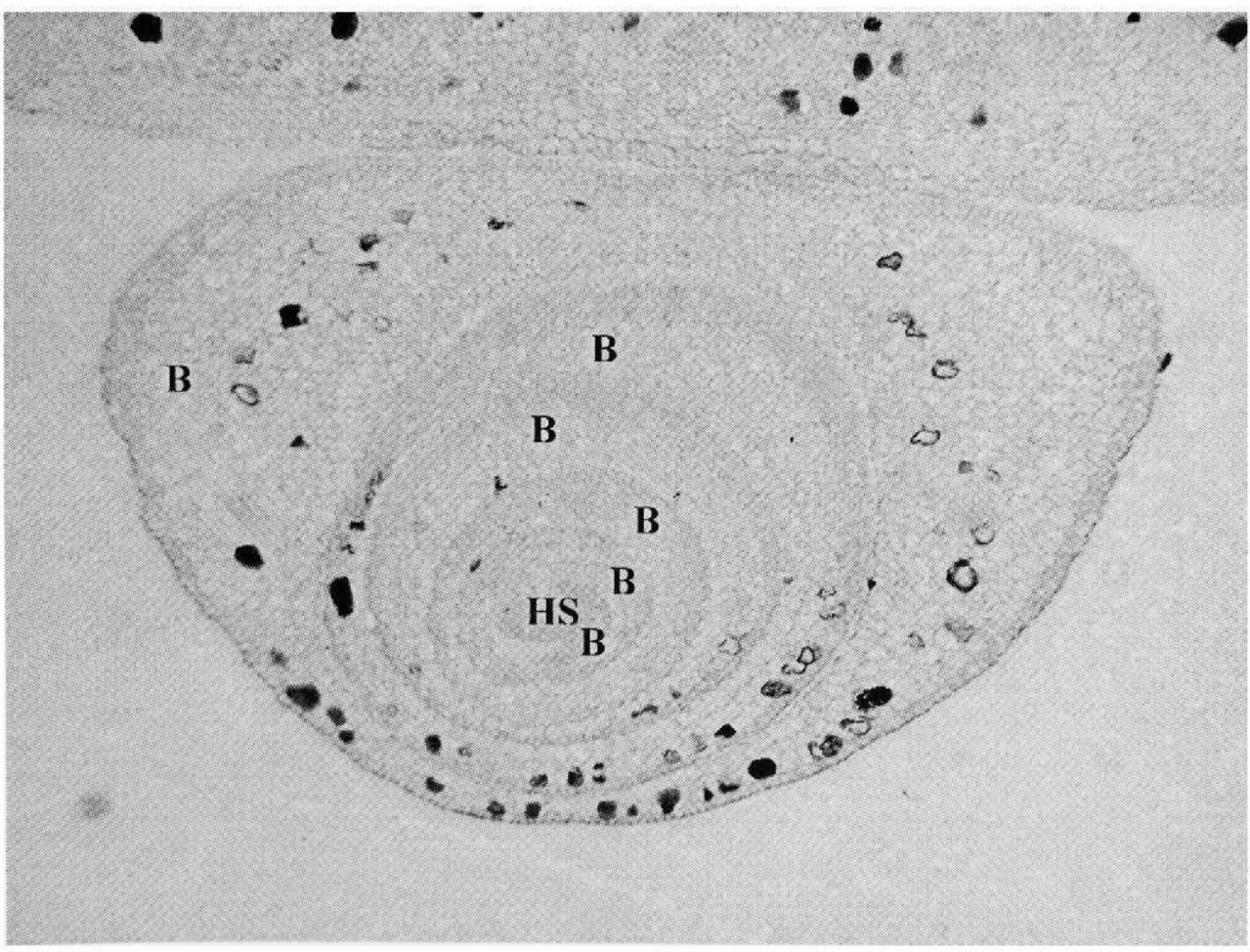


Figure 1.16. HS to VS transition. Peg-like shoot shown (Culm 1). Asterisks mark nodes along the HS.

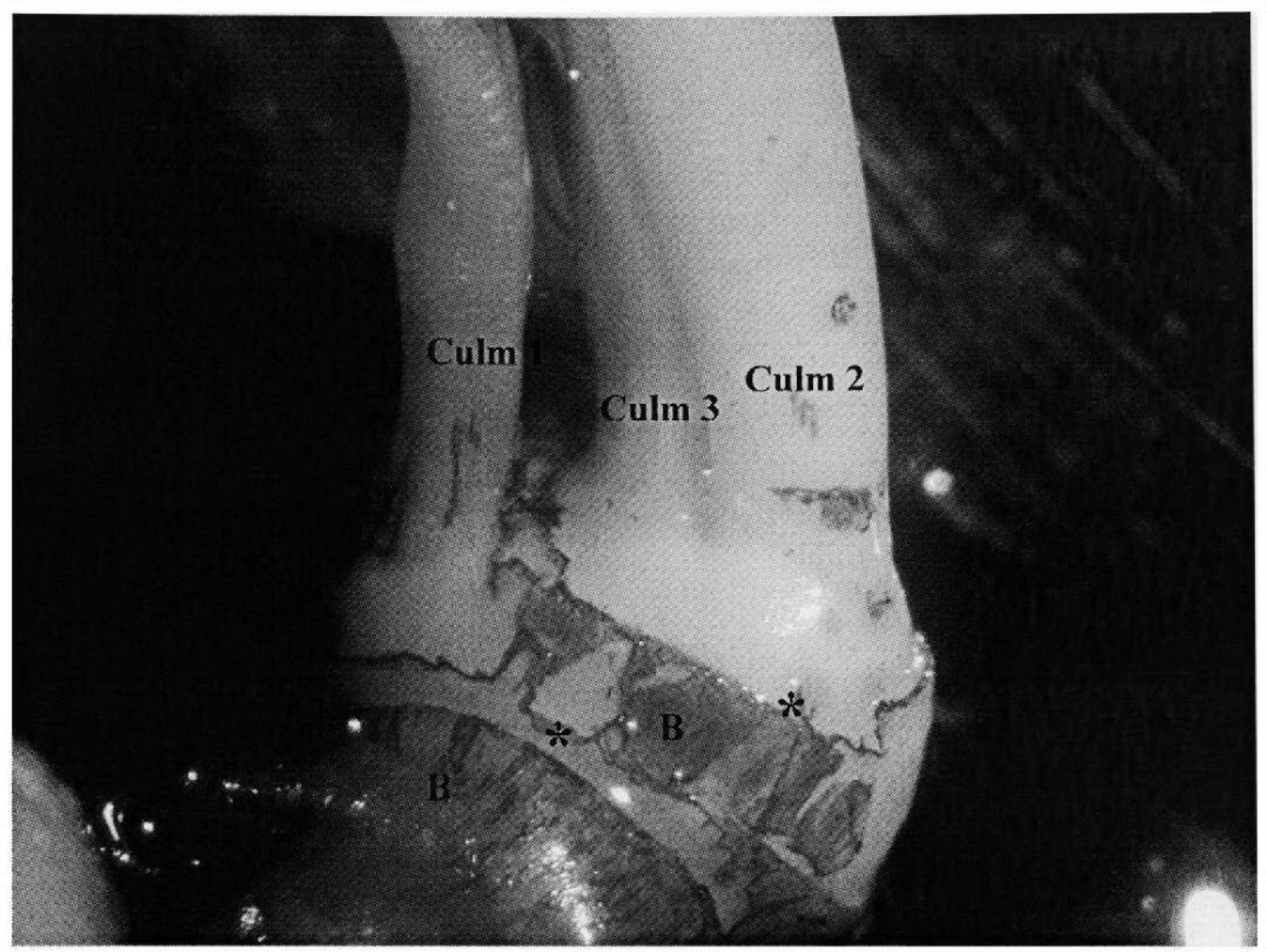


Figure 1.17. Regression of culm diameter versus culm length and diameter for October 2003 (A) and April 2004 (B).

A.

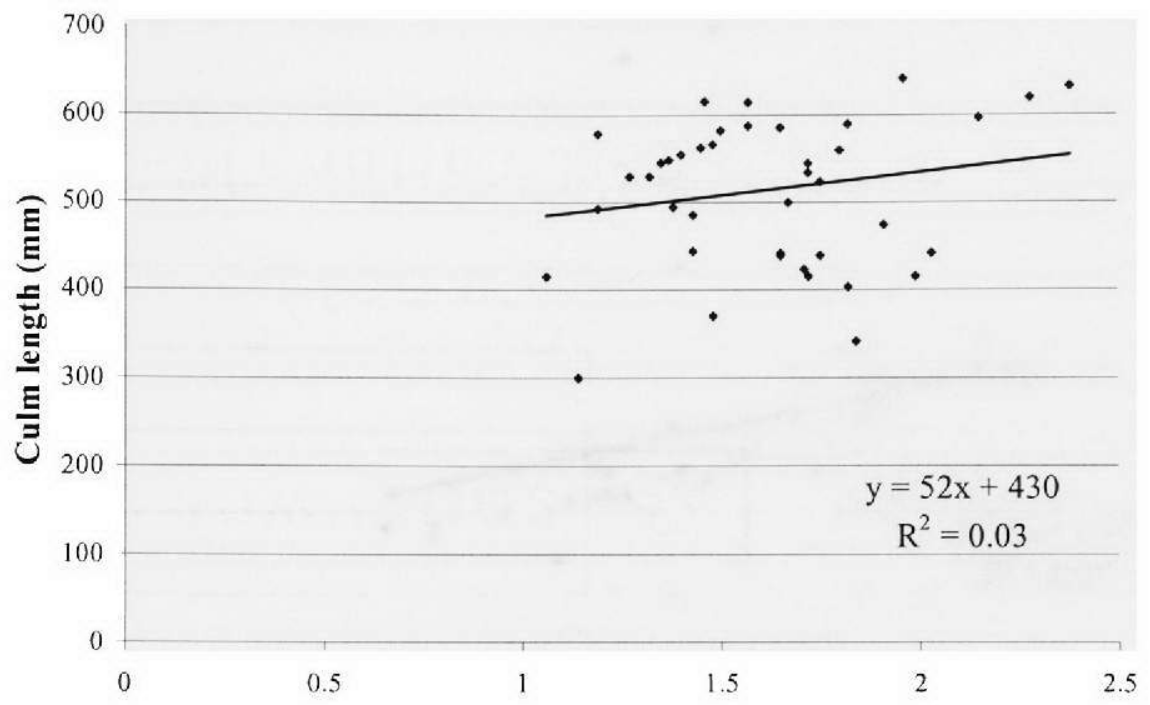

Culm diameter (mm)

B.

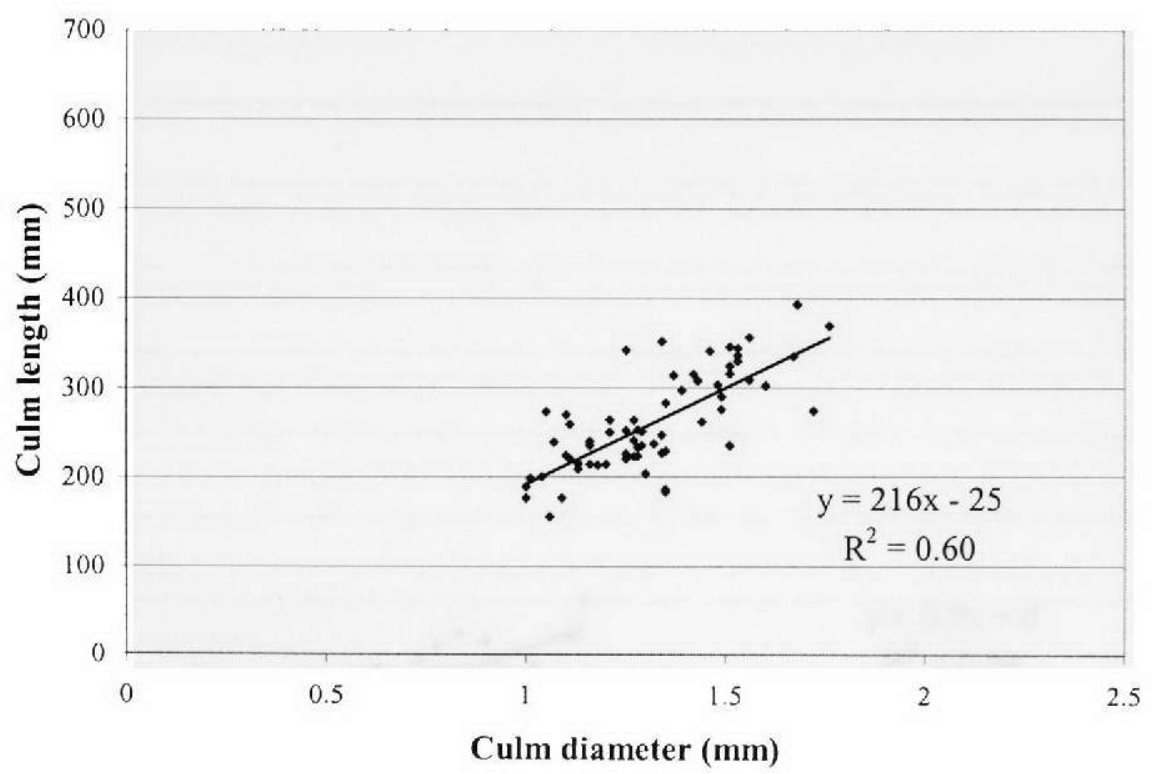


Figure 1.18. Regression of leaf bract length of $\mathrm{B} 2$ and leaf bract length of $\mathrm{B} 3$ for October 2003 (A) and April 2004 (B).

A.

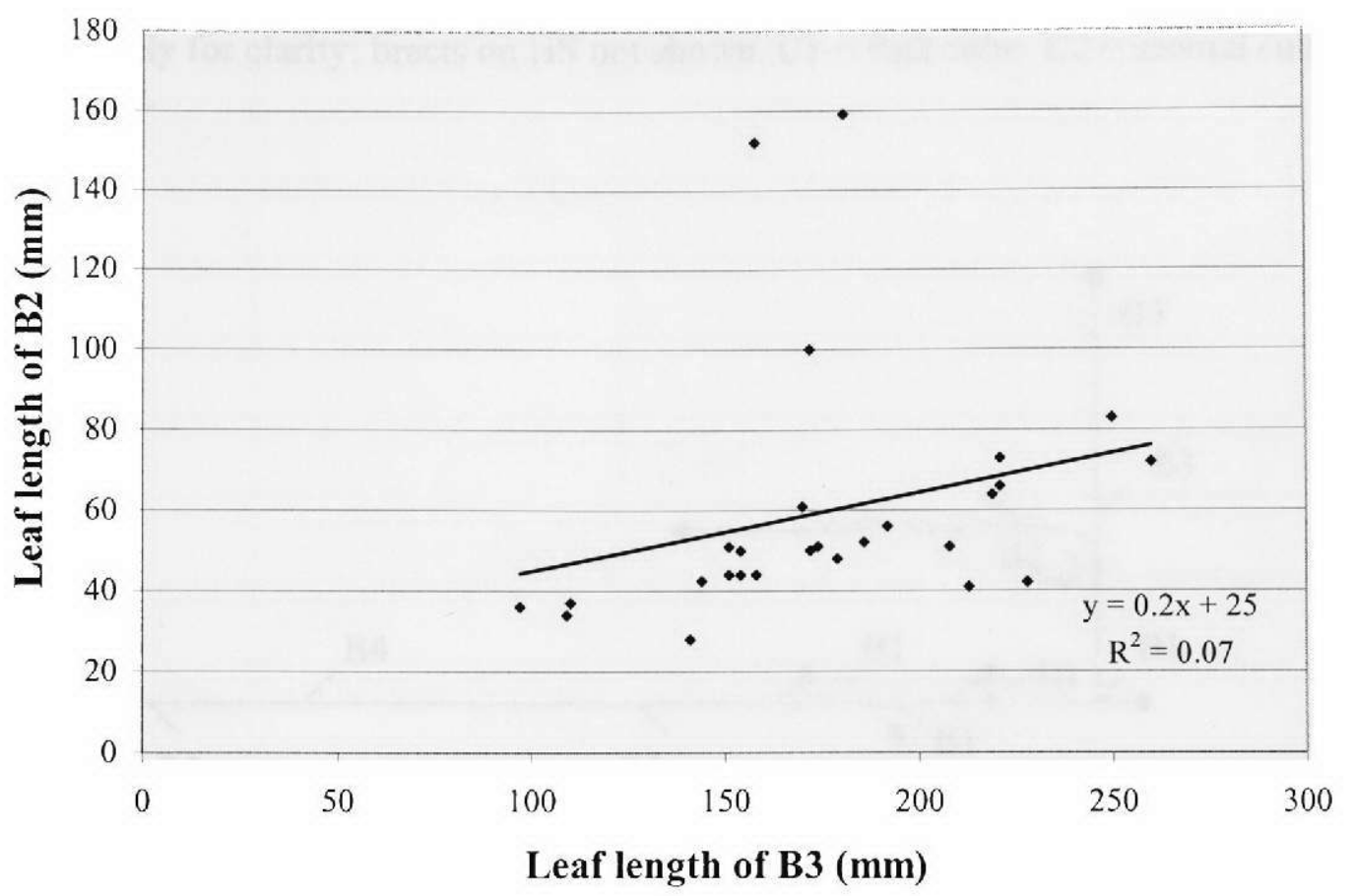

B.

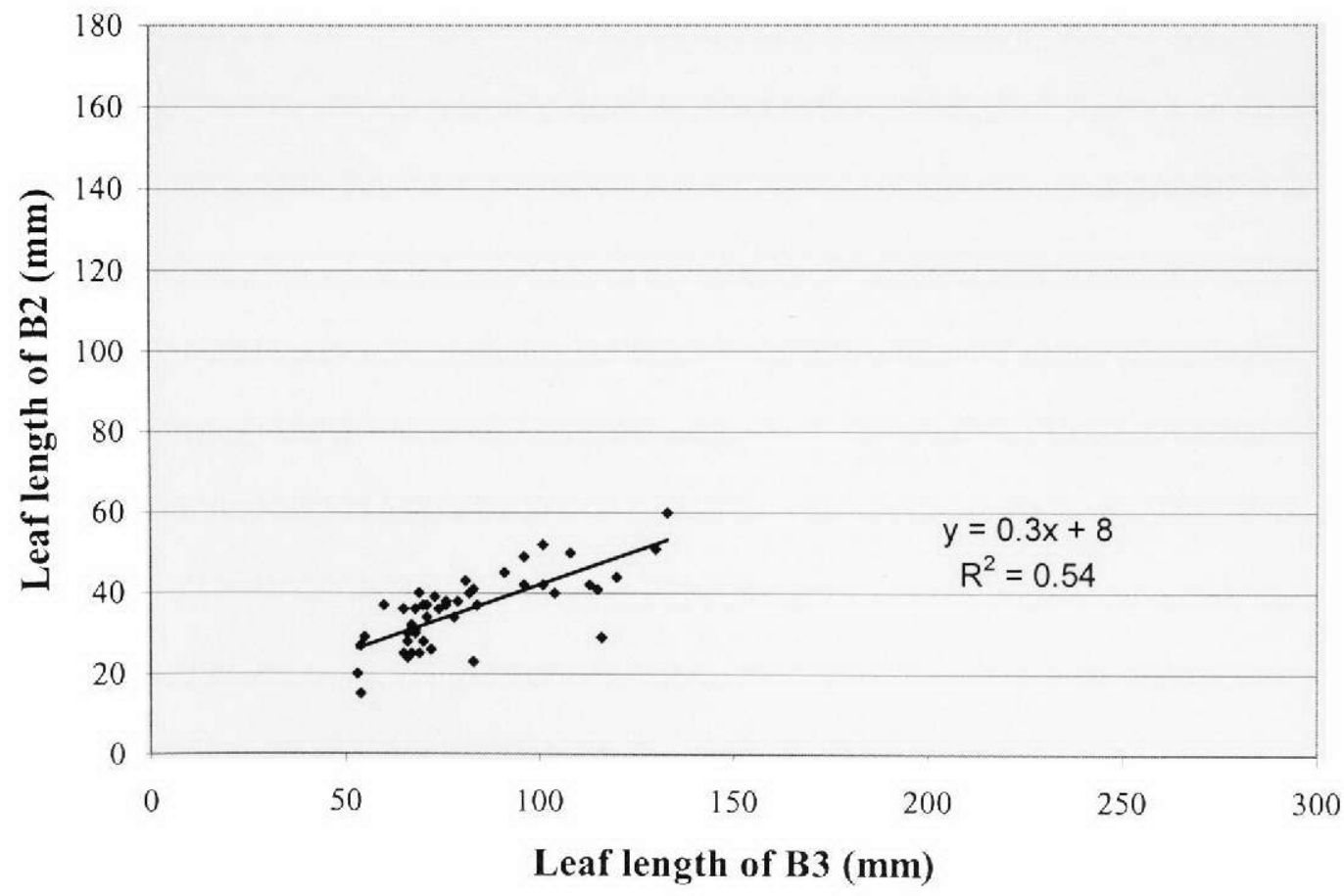


Figure 1.19. Patterns of growth for Eleocharis cellulosa. A. Model of growth showing long internodes and the transition from monopodial to sympodial growth. Culm-peg is an undeveloped sympodial unit that grows larger over time. B. Model of growth showing renewal of HS after several culms have been produced. Vertical shoot has been enlarged horizontally for clarity; bracts on HS not shown. $\mathrm{C} 1=$ first culm, $\mathrm{C} 2=$ second culm, $\mathrm{C} 3=$ third culm.

A.

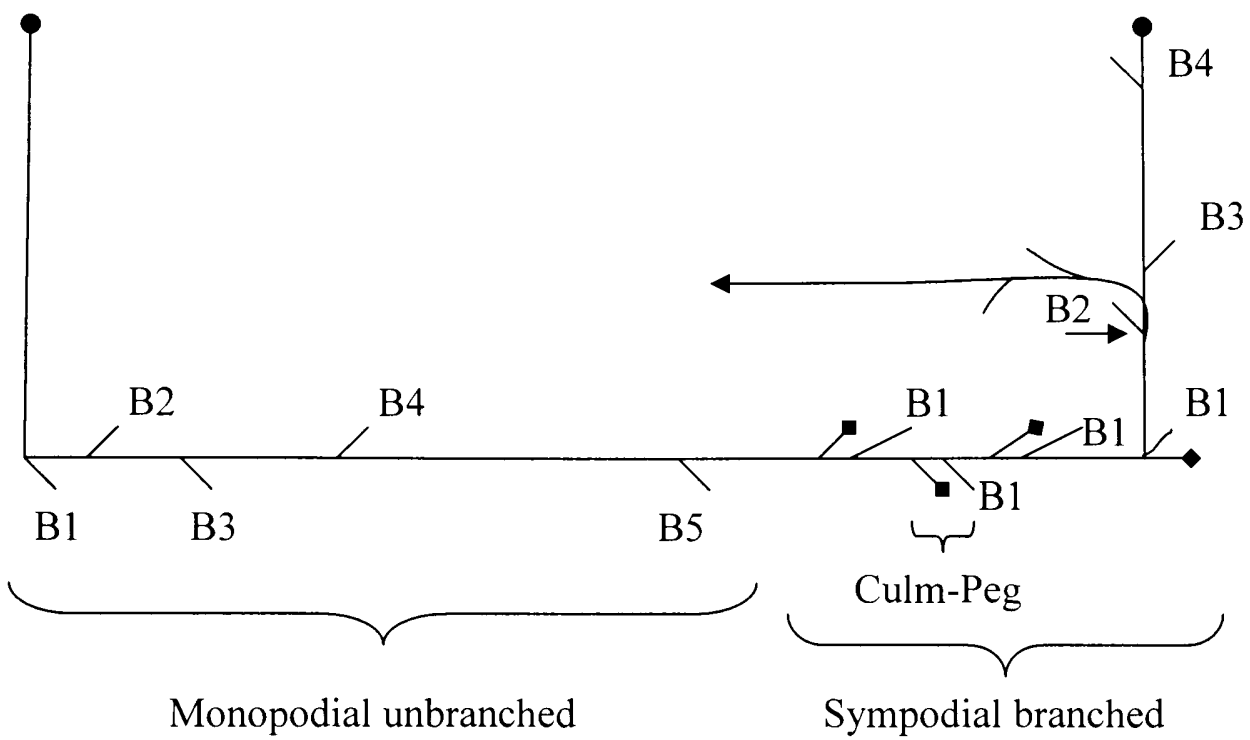


B.

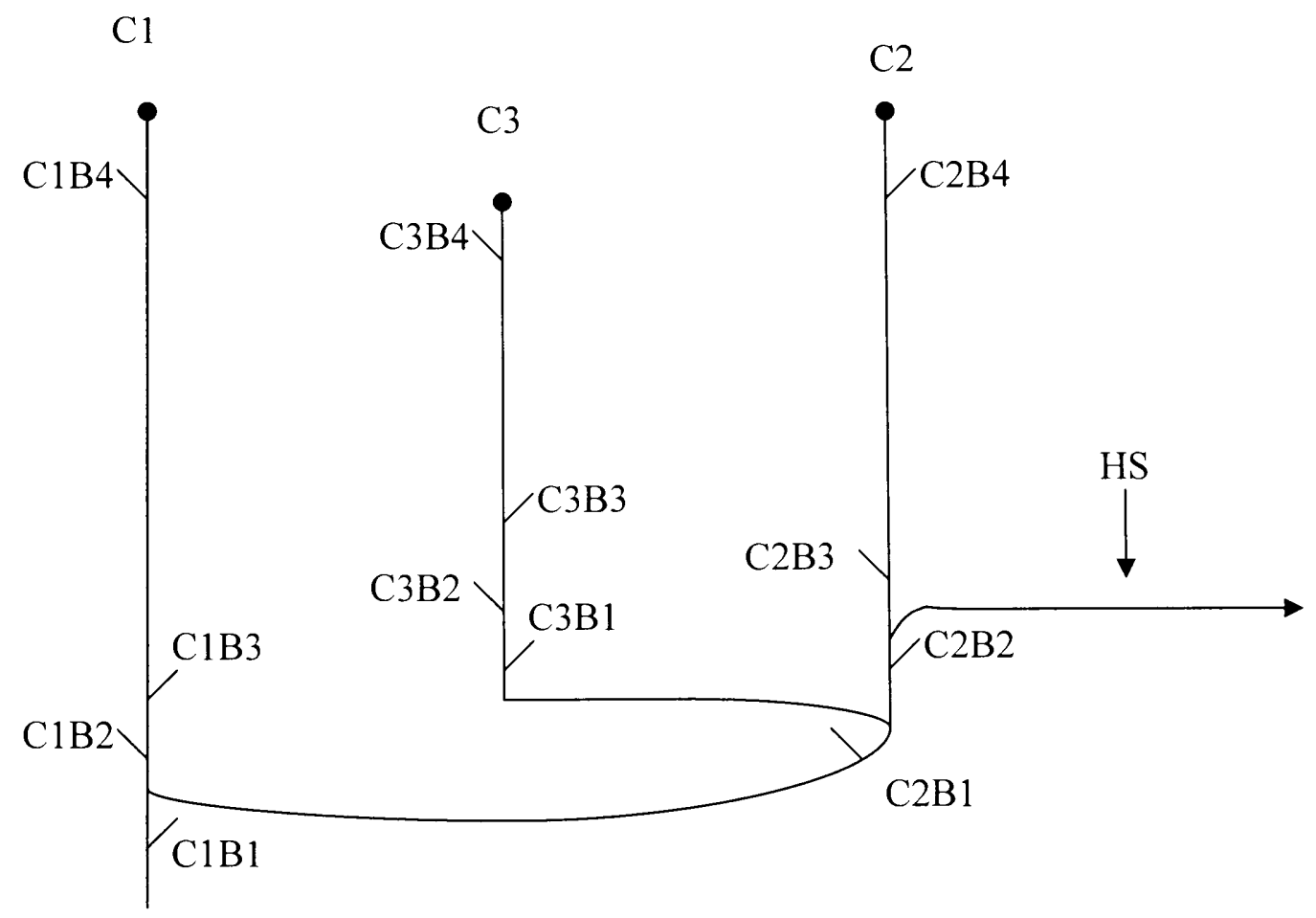


Chapter 2

Effects of nutrient additions on the growth and morphology of E. cellulosa 


\section{INTRODUCTION}

Historically, the Everglades and coastal ecosystems of South Florida were a large landscape connected by broad sheetflow of very low nutrient water (Harwell 1998). Alterations of hydrologic regimes and water quality in these ecosystems have led to changes in vegetation. Surface water run-off from adjacent agricultural activities have contributed to increases in surface water nutrients, soil $\mathrm{P}$ and standing plant biomass (Newman et al. 1996). One consequence of eutrophication of a plant community is an increase in emergent plant biomass (McJannet et al. 1995). If a plant is nutrient limited, its production increases in response to addition of the limiting nutrient. This relationship between nutrient availability and productivity provides an objective criterion for evaluating the extent of nutrient limitation to the growth of individual plants or monospecific stands (Chapin et al. 1986). Eleocharis cellulosa is distributed throughout Florida (Tobe et al. 1998), which suggests that it is found in both high and low nutrient areas and that it can grow in different nutrient conditions.

Because E. cellulosa has a shoot system that has both orthotropic and plagiotropic components, increased productivity could favor production of one type of shoot alone, both types differentially, or both equally. I intended to study the effects of increased nutrient levels on E. cellulosa growth and morphology to determine how it responds phenotypically to different nutrient levels. I examined variation in number and size of aerial shoots, leaves, horizontal shoots (HS) and internodes in response to different levels of added $\mathrm{N}, \mathrm{P}$ and $\mathrm{N}$ and $\mathrm{P}$. Unfortunately I was unable to accomplish my experiment because of high levels of nitrogen and phosphorus in all treatments as well the control 
experiments. I was able, however, to determine biomass partitioning in E. cellulosa, as well tissue nutrient content and make comparisons to field data. 


\section{MATERIALS AND METHODS}

A randomized block design was used in the fertilization experiment, where four treatments were performed on a total of forty-eight plants. E. cellulosa plants were

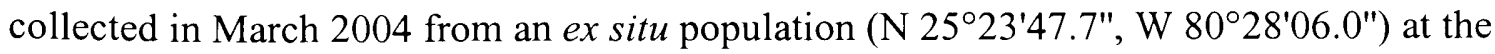
Florida International University (FIU)-Singeltary site south of Florida City. Initially, the number of culms, length of culms and culm diameter were measured and plants were trimmed to three upright culms per plant. All horizontal shoots (HSs) were removed, but roots were left intact. Each plant was planted in a plastic container that contained a 3:1 ratio of commercial potting soil (Scott's Metro Mix 500 potting soil, Scott's Miracle Grow, Marysville, Ohio) to sand. Altogether, $1.36 \mathrm{~kg}$ of soil mixture was added to each container. Water was added to containers to maintain the water level $5 \mathrm{~cm}$ above the soil. The sand allowed the soil and E. cellulosa plants to stay submerged in water. Beginning in March 2004, plants were acclimated in the greenhouse for one month. They were watered regularly to maintain water levels. After one month, plants were randomly assigned to one of four treatments, with 12 plants per treatment. The plants were organized into six blocks with eight plants per block and in each block there were two replicates of each treatment. The treatments consisted of nitrogen and phosphorus additions at levels used by Newman et al. (1996) in a 2-year study of the effects of nutrient addition on Everglades wet prairie species. The treatments were as follows:

1. Low nitrogen, low phosphorus (LNLP): no nutrients added.

2. High nitrogen, low phosphorus (HNLP): (1mg/L NO $3-\mathrm{N}$ or $1 \mathrm{ppm})$ added as potassium nitrate.

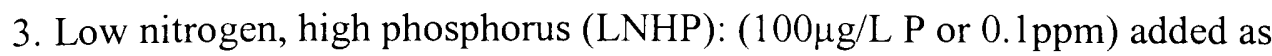


sodium phosphate monobasic.

4. High nitrogen, high phosphorus (HNHP): (1mg/L $\mathrm{NO}_{3}-\mathrm{N}$ or $1 \mathrm{ppm}, 100 \mu \mathrm{g} / \mathrm{L} \mathrm{P}$

or $0.1 \mathrm{ppm}$ ) added as potassium nitrate and sodium phosphate monobasic.

The LNLP treatment, in which plants obtained nutrients from the soil-sand mixture in which they were planted, was watered with distilled water alone. For the other three treatments, nutrient solutions were made up from stock solutions and added to each plant. The nutrient solutions were changed once a week to replenish nutrients lost through uptake. This was done by suctioning off the old solution with a pipet and replacing it with freshly-made solution. The plants remained in the FIU research greenhouse and were not moved from their original positions during the experiment. Treatments began in May 2004, and E. cellulosa plants were harvested in July 2004 after 8 weeks. Numbers of new upright culms, lengths of culms, culm diameters, numbers of new HSs, lengths of HS, numbers of internodes per HS and lengths of internodes per HS were measured on each plant. The numbers of inflorescences per plant was also recorded. Plants were separated into the vertical shoot (VS), HS, roots, and culms, with the culms being further subdivided into the original culms that were cut, new culms that were brown all the way to the tip (dead culms) and new culms that were at least partially green. These parts were dried at $70{ }^{\circ} \mathrm{C}$ to constant weight and then weighed. A subset of soil, new live culms and the vertical shoot base were analyzed for nitrogen and phosphorus content. These samples were ground to a fine powder and processed. For nitrogen analysis, the samples were run on a FISONS Elemental Analyzer 1500 (Fisons Instruments inc., Beverly, Massachusetts). For phosphorus analysis, a phosphorus colormetric determination 
method was used (Fourqurean et al. 1992). These analyses were performed in the FIU Seagrass Ecosystems Research Lab (SERL).

Statistical analysis. All statistics were performed using Microsoft Windows XP Excel (Microsoft Inc., Seattle, WA) and SPSS 13.0 statistical package for Windows (SPSS Inc., Chicago, IL). A randomized block design was used for the experimental set up in order to account for possible positional differences in placement of plants in the greenhouse. The 48 E. cellulosa plants were separated into 4 treatments, so there were a total of twelve plants per treatment. These plants were arranged into 6 blocks with 2 plants per treatment in each block. The 8 plants were assigned random positions in the block using random numbers generated in Excel. ANOVA or Kruskall-Wallis tests of significance were used to asses the effects of nitrogen and phosphorus. Post-hoc pairwise comparisons were made using Tukey's HSD procedure.

Data for morphological parameters that did not differ significantly among treatments were combined across treatments and analyzed with data from field-collected plants (Chap. 1) using ANOVA or Kruskall-Wallis tests in order to compare growth of plants in greenhouse conditions to field conditions. Data was also transformed into percentages. When multiple measurements per plant were available, an average per plant was calculated, so that comparisons are for values among plants in the field vs. plants in the greenhouse. 


\section{RESULTS}

Soil nutrient analyses. Nutrient levels for the 1 pre-treatment sample for which data was available were $7 \% \mathrm{C}, 0.1 \% \mathrm{~N}(992 \mathrm{ppm}$ or $992 \mathrm{mg} / \mathrm{L})$ and $0.3 \% \mathrm{P}(2776 \mathrm{ppm}$ or $2776 \mu \mathrm{g} / \mathrm{g}$ ). Nutrient solution addition did not change soil nutrient content, as there were no significant differences in soil $\mathrm{N}$ and $\mathrm{P}$ among treatments at the end of the experiment (Table 2.1).

Architectural responses to nutrient addition. Eleocharis cellulosa's morphology did not differ among blocks in any of the measured parameters, as two-way ANOVA tests of block effects showed no significant differences $(P>0.05)$. This indicates that differences that resulted from the positions of plants in the greenhouse were minor, and any differences observed among groups were due to random variation. Data from the different blocks were therefore combined for further analyses.

Plants produced new culms, inflorescences, horizontal shoots and vertical shoots during the experiment (Table 2.2). Treatments did not differ significantly in the number or size of these plant parts, except for culm length (Table 2.2). Culms were longest in LNHP treatments. Differences among the sample means for other parameters could be due to chance variation (Table 2.2).

Data, which did not differ significantly, were combined to determine general growth rates and production. The greenhouse-grown plants produced an average of 5.6 culms, equally divided between vegetative and reproductive, over the course of the experiment. Thus, the rate of production of culms was 2.8 per month. The same plants produced 5.2 horizontal shoot or ramets over the course of the experiment, for a rate of production of 2.6 ramets per month. Thus, the expansion of B1 buds (total culms) and 
B2 buds (horizontal shoots) was approximately equal, as the ratio of B2 buds to B1 buds was 0.97 . The total number of shoots expanded was 10.8 , or a rate of 5.4 shoots (culms and horizontal shoots) per month.

Plant tissue nutrient response to nutrient addition. Plant $\mathrm{C}, \mathrm{N}$ and $\mathrm{P}$ content also did not differ significantly among treatments either in the culms or the vertical shoots (Table 2.1). Analysis of the combined data showed that there were no significant $(\mathrm{P}>0.05)$ differences in $\mathrm{P}$ levels between culms and vertical shoots but there were significant differences between levels of $\mathrm{C}(\mathrm{P}<0.05)$ and levels of $\mathrm{N}(\mathrm{P}<0.05)$ between culms and vertical shoots. Culms had $41.28 \pm 0.64 \% \mathrm{C}, 1.18 \pm 0.11 \% \mathrm{~N}, 0.18 \pm 0.15 \%$ $P$, while vertical shoots had $43 \pm 1.01 \% \mathrm{C}, 0.62 \pm 0.02 \% \mathrm{~N}, 0.23 \pm 0.06 \% \mathrm{P}$.

Biomass partitioning. E. cellulosa's biomass partitioning, or investment in culms, vertical shoots, ramets, and roots, was similar among treatments (Table 2.3). Similarly, partitioning into upright shoots or shoots and roots also did not differ significantly. When data were summed across treatments, E. cellulosa invested more in culms than in the supporting stem (53\% in culms and $13 \%$ in VS's, Figure 2.1$)$. Horizontal shoots, which were an investment in outgrowth of the $\mathrm{B} 2$ bud, were $18 \%$ of the total biomass, and investment in roots was relatively low (16\%) (Figure 2.1).

Comparison of morphology of greenhouse-grown plants to field-collected plants. Significant differences were found in morphological parameters from the field plants in October, April and the greenhouse-grown plants collected from the same site and grown from April to July (Table 2.5). Pairwise comparisons showed that internode two (its position on HS) was significantly different between October data and experimental data (Table 2.5). 


\section{DISCUSSION}

Soil nutrient analyses. Although different amounts of nutrients were added in solution, nutrient additions did not affect soil nutrient levels (Table 2.1). The level of $\mathrm{P}$ was high compared to known levels of $\mathrm{P}$ found in the Everglades, while the $\mathrm{N}$ content is low (Newman et al., 1997); these nutrient levels were much greater than the amounts added in the nutrient solutions. Soil from three sites on FIU's Singeltary property was examined for $\mathrm{C}, \mathrm{N}, \mathrm{P}$ and the levels of nutrients were lower compared to levels found at the end of my experiment (personal communication, Jennifer Richards). The lack of differences among treatments is probably because the amounts added, although high for nutrients in Everglades water for the high treatments, were much less than the amounts in the potting soil. Additionally, nutrients added in solution can take several years to enter the soil compartment in the Everglades ecosystem (Noe et al. 2001, Gaiser et al. submitted).

Architectural responses to nutrient addition. Because of the high levels of nutrients in the soil, we can assume that $\mathrm{N}$ and $\mathrm{P}$ were not limiting plant growth under the experimental conditions. Under these experimental conditions, E. cellulosa grew and produced culms, HSs and roots. In a study comparing $\mathrm{N}$ and $\mathrm{P}$ tissue concentrations across the habitats and functional groups of 41 wetland plants, the habitats that were observed were infertile and fertile habitats (McJannet et. al. 1995). The infertile habitat was classified by plants that grew in sand and gravel and had $\mathrm{N}$ and $\mathrm{P}$ soil levels below $10 \mathrm{ppm}$. This study grew wetland plants native to both infertile and fertile habitats in high nutrient conditions using fertilizer. This included Eleocharis erythropoda, E. palustris and E. ovata. There were no significant differences in nutrient content between plants 
from infertile habitats and fertile habitats. This may be because plants native to low nutrient habitats are not as plastic in root or shoot morphology and show less phenotypic variation in response to nutrient stress. (McJannet et al. 1995). Species from infertile soils typically have a low relative growth rate and high root to shoot ratio while species from fertile soils have higher growth rates and low root to shoot ratios (Chapin 1980, 1986).

Biomass partitioning. It is difficult to estimate biomass partitioning in fieldgrown plants, as collection of belowground parts, both roots and rhizomes, is difficult. Growth of individual plants in artificial containers allows a more accurate estimate of this investment. This study showed that in relatively high nutrient conditions and shallow water, plants invest significantly more in photosynthetic apparatus and sexual reproduction than in vegetative reproduction, with a relatively small investment in roots. This is consistent with results of other studies, where higher levels of limiting nutrients result in less biomass investment in nutrient-gathering structures. Plants were grown in fixed levels of water, approximately $8 \mathrm{~cm}$ in depth from the surface of the water to the soil layer. A previous study on E. cellulosa where plants were grown at differing water depths, showed that aboveground biomass (culms) did not differ significantly among fixed water level treatments of $7 \mathrm{~cm}$ and $54 \mathrm{~cm}$. This study also showed there was more investment in culms than in roots and rhizomes in E. cellulosa for both treatments. In my experiment, there was also more investment in the culms than in roots and rhizomes (Table 2.3). In a study that looked at growth of E. interstincta, Typha domingensis, and Cladium jamaicense in outdoor tanks at different nutrient and water levels for two years, there were significant effects on aboveground biomass found among nutrient concentrations and water depth for all species. Effects of treatments on growth developed 
over time (Newman et. al. 1996). In a previous study (Edwards et al. 2003), different water depth levels did not affect aboveground biomass. The study by Newman et al. (1996) suggests that $E$. cellulosa aboveground biomass production is not only affected by nutrients but by water depth and time.

Conclusions. $\mathrm{N}$ and $\mathrm{P}$ were not limiting plant growth in the experiment. The higher levels of nutrients provided in the experiment, as compared to field conditions, caused E. cellulosa to grow and produce culms, HSs and roots in a relatively short time. Biomass partitioning showed that plants invested significantly more in photosynthetic apparatus and sexual reproduction with a relatively small investment in roots. Previous studies indicated that plant growth and morphology are not only affected by nutrients but also by water depth and time but neither were examined in this experiment. 


\section{LITERATURE CITED}

CHAPIN III, F.S. 1980. The mineral nutrition of wild plants. Annual Review of Ecology and Systematics 11:233-260.

CHAPIN III, F.S., VITOUSEK, P.M and K. VAN CLEVE. 1986. The nature of nutrient limitation in plant communities. American Naturalist 127(1): 48-58.

EDWARDS, A.L., LEE, D.W. and J.H. RICHARDS. 2003. Responses to a fluctuating environment: effects of water depth on growth and biomass allocation in Eleocharis cellulosa Torr. (Cyperaceae). Canadian Journal of Botany 81: 964-975.

FOURQUREAN, J.W., J.C. ZIEMAN, and G.V.N. POWELL. 1992.

Phosphorus limitation of primary production in Florida Bay: Evidence from the C:N:P ratios of the dominant seagrass Thalassia testudinum. Limnology and Oceanography 37:162-171.

GAISER, E.E., J.C. TREXLER, J.H. RICHARDS, D.L. CHILDERS, D. LEE, A.L. EDWARDS, L.J. SCINTO, K. JAYACHANDRAN, G.B. NOE, R.L. JONES. 2005. Cascading ecological effects of low-level phosphorus enrichment in the Florida Everglades. Journal of Environmental Quality 34: 717-723.

HARWELL, M. I998. Freshwater systems science and environmental decision making in south Florida. Ecological Applications 8 (3): 580-590.

MCJANNET, C.L., KEDDY, P.A., and F.R. PICK. 1995. Nitrogen and phosphorus tissue concentrations in 41 wetland plants: a comparison across habitats and functional groups. Functional Ecology 9(2): 231-238.

NEWMAN, S., GRACE, J.B. and J.W. KOEBEL. 1996. Effects of nutrients and hydroperiod on Typha, Cladium, and Eleocharis: Implications for Everglades restoration. Ecological Applications, 6(3) 774-783.

NEWMAN, S., K. R. REDDY, W. F. DEBUSK, Y. WANG, G. SHIH, and M. M. FISHER. 1997. Spatial distribution of soil nutrients in a northern Everglades marsh: Water conservation area 1. Soil Science Society of America Journal 61: 1275-1283.

NOE, G. B., D. L. CHILDERS, and R. D. JONES. 2001. Phosphorus biogeochemistry and the impact of phosphorus enrichment: Why is the Everglades so unique? Ecosystems 4: 603-624. 
TOBE, J.D., K.C. BURKS and R.W. CANTRELL. 1998. Florida wetland plants: An identification manual. pp. 65-67. University of Florida Press, Gainesville, Florida, USA. 
Table 2.1. Summary of means \pm 1 S.E for percent $\mathrm{C}, \mathrm{N}$, and $\mathrm{P}$ in E. cellulosa. One-way Kruskall-Wallis tests among treatments were performed on nutrient content of $E$.

cellulosa. DF $=3$ for both tests. There were no results found below 0.05 , therefore nonsignificant results were found for all variables. $\mathrm{N}_{\text {soil }}, \mathrm{N}_{\text {culms }}$ and $\mathrm{N}_{\text {vertical shoots }}=12$.

Variable

$\begin{array}{llll}\text { LNLP } & \text { HNLP } & \text { LNHP } & \text { HNHP }\end{array}$

$(\%)$

$(\%)$

$(\%)$

Soil
$\mathrm{C}$
$21.64 \pm 11.33$
$33.99 \pm 8.00$
$21.10 \pm 17.07$
$40.82 \pm 2.87$
0.319
$\mathrm{N}$
$0.24 \pm 0.14$
$0.41 \pm 0.09$
$0.28 \pm 0.23$
$0.52 \pm 0.02$
0.340
$\begin{array}{lll}P & 0.20 \pm 0.10 & 0.26 \pm 0.110\end{array}$
$0.13 \pm 0.10$
$0.27 \pm 0.12$
0.740

\section{Culms}

$\begin{array}{llllll}\mathrm{C} & 40.82 \pm 0.23 & 42.00 \pm 1.17 & 41.39 \pm 0.27 & 40.92 \pm 0.91 & 0.691 \\ \mathrm{~N} & 1.28 \pm 0.12 & 1.21 \pm 0.10 & 1.11 \pm 0.06 & 1.11 \pm 0.15 & 0.669 \\ \mathrm{P} & 0.14 \pm 0.11 & 0.15 \pm 0.14 & 0.16 \pm 0.11 & 0.26 \pm 0.24 & 0.913\end{array}$

Vertical Shoots

$\begin{array}{llllll}\mathrm{C} & 44.15 \pm 1.22 & 43.7 \pm 0.55 & 41.19 \pm 1.87 & 44.29 \pm 0.66 & 0.361 \\ \mathrm{~N} & 0.61 \pm 0.02 & 0.67 \pm 0.01 & 0.64 \pm 0.04 & 0.56 \pm 0.03 & 0.119 \\ \mathrm{P} & 0.17 \pm 0.07 & 0.32 \pm 0.06 & 0.22 \pm 0.11 & 0.23 \pm 0.02 & 0.514\end{array}$


Table 2.2. Summary of statistics for treatment effects on E. cellulosa growth. Mean \pm 1

S.E. Summary of one way analysis of variance for treatment effects on plant growth.

Degrees of freedom $=3$. Significant results $(\mathrm{P}<0.05)$ shown in bold; italicized parameters indicate $\mathrm{P}<0.1$. LNLP $=$ Low nitrogen, low phosphorus, $\mathrm{HNLP}=\mathrm{High}$ nitrogen, low phosphorus, $\mathrm{LNHP}=$ Low nitrogen, high phosphorus, $\mathrm{HNHP}=\mathrm{High}$ nitrogen, high phosphorus.

\begin{tabular}{|c|c|c|c|c|c|}
\hline Variable & $\begin{array}{l}\text { LNLP } \\
(\operatorname{trt} 1)\end{array}$ & $\begin{array}{l}\text { HNLP } \\
(\operatorname{trt} 2)\end{array}$ & $\begin{array}{l}\text { LNHP } \\
(\operatorname{trt} 3)\end{array}$ & $\begin{array}{l}\text { HNHP } \\
(\operatorname{trt} 4)\end{array}$ & $\begin{array}{l}\mathrm{P} \text { - } \\
\text { value }\end{array}$ \\
\hline $\begin{array}{l}\text { Number of vegetative culms } \\
\text { per plant }\end{array}$ & $\begin{array}{l}3.2 \pm \\
0.4 \\
(12)\end{array}$ & $\begin{array}{l}2.9 \pm \\
0.3 \\
(12)\end{array}$ & $\begin{array}{l}2.8 \pm \\
0.5 \\
(12)\end{array}$ & $\begin{array}{l}2.3 \pm \\
0.3 \\
(12)\end{array}$ & 0.46 \\
\hline Culm length (mm) & $654 \pm 20$ & $621 \pm 22$ & $657 \pm 23$ & $727 \pm 23$ & 0.012 \\
\hline Culm diameter $(\mathrm{mm})$ & $\begin{array}{l}1.70 \pm \\
0.07\end{array}$ & $\begin{array}{l}1.80 \pm \\
0.05\end{array}$ & $\begin{array}{l}1.81 \pm \\
0.05\end{array}$ & $\begin{array}{l}1.86 \pm \\
0.05\end{array}$ & 0.23 \\
\hline $\begin{array}{l}\text { Number of inflorescences per } \\
\text { plant }\end{array}$ & $\begin{array}{l}2.2 \pm 0.3 \\
(11)\end{array}$ & $\begin{array}{l}2.7 \pm 0.4 \\
(11)\end{array}$ & $\begin{array}{l}3.3 \pm 0.3 \\
(12)\end{array}$ & $\begin{array}{l}3.2 \pm 0.3 \\
(12)\end{array}$ & 0.08 \\
\hline $\begin{array}{l}\text { Total number of culms per } \\
\text { plant (vegetative } \\
\text { reproductive) }\end{array}$ & $\begin{array}{l}5.3 \pm \\
0.5 \\
(12)\end{array}$ & $\begin{array}{l}5.6 \pm \\
0.4 \\
(12)\end{array}$ & $\begin{array}{l}5.5 \pm \\
0.4 \\
(12)\end{array}$ & $\begin{array}{l}6.1 \pm \\
0.4 \\
(12)\end{array}$ & 0.70 \\
\hline Number of HSs per plant & $\begin{array}{l}4.7 \pm 0.4 \\
(12)\end{array}$ & $\begin{array}{l}4.7 \pm 0.6 \\
(12)\end{array}$ & $\begin{array}{l}4.8 \pm 0.6 \\
(12)\end{array}$ & $\begin{array}{l}6.6 \pm 0.7 \\
(12)\end{array}$ & 0.07 \\
\hline HS length (mm) & $117 \pm 5$ & $115 \pm 5$ & $112 \pm 5$ & $105 \pm 3$ & 0.21 \\
\hline Number of internodes per $H S$ & $\begin{array}{l}5.7 \pm 0.2 \\
(12)\end{array}$ & $\begin{array}{l}5.9 \pm 0.1 \\
(12)\end{array}$ & $\begin{array}{l}5.8 \pm 0.1 \\
(12)\end{array}$ & $\begin{array}{l}6.2 \pm 0.1 \\
(12)\end{array}$ & 0.09 \\
\hline Length of internodes (mm) & $19 \pm 1$ & $19 \pm 1$ & $19 \pm 1$ & $17 \pm 1$ & 0.18 \\
\hline Length of internode $2(\mathrm{~mm})$ & $99 \pm 16$ & $106 \pm 13$ & $102 \pm 4$ & $93 \pm 10$ & 0.88 \\
\hline
\end{tabular}


Table 2.3. Summary of means \pm 1 S.E for biomass in dry weight and biomass allocation of $E$. cellulosa plants under different nutrient treatments. The Kruskall-Wallis and oneway ANOVA significance tests performed on biomass for E. cellulosa. ANOVA in g/dw. Kruskall-Wallis in percentage. $\mathrm{DF}=3$ for both tests. There were no results found below 0.05 , therefore non-significant results were found for all variables. Abbreviations as in Table 2.1. A. Dry weight data in grams. B., C., Biomass allocation data as percentages.

A.

\begin{tabular}{lccccc}
\multicolumn{1}{c}{ Variable } & $\begin{array}{c}\text { LNLP } \\
\text { (trt1 })\end{array}$ & $\begin{array}{c}\text { HNLP } \\
(\operatorname{trt} 2)\end{array}$ & $\begin{array}{c}\text { LNHP } \\
(\operatorname{trt} 3)\end{array}$ & $\begin{array}{c}\text { HNHP } \\
(\operatorname{trt} 4)\end{array}$ & P-value $^{\text {A }}$ \\
Cut culms (g) & $0.20 \pm 0.04$ & $0.17 \pm 0.05$ & $0.17 \pm 0.03$ & $0.19 \pm 0.04$ & 0.916 \\
New culms (g) & $1.23 \pm 0.15$ & $1.25 \pm 0.12$ & $1.46 \pm 0.15$ & $1.19 \pm 0.13$ & 0.555 \\
Vertical shoot (g) & $0.36 \pm 0.04$ & $0.32 \pm 0.05$ & $\begin{array}{c}0.39 \pm \\
0.04\end{array}$ & $0.32 \pm 0.05$ & 0.603 \\
Roots (g) & $0.43 \pm 0.06$ & $0.39 \pm 0.04$ & $0.50 \pm 0.07$ & $0.40 \pm 0.05$ & 0.531 \\
Ramet (g) & $0.56 \pm 0.15$ & $0.58 \pm 0.14$ & $0.40 \pm 0.09$ & $0.50 \pm 0.14$ & 0.766
\end{tabular}

B.

Variable

Culms \%

VS \%

Ramet \%

Roots \%
LNLP

$(\operatorname{trt} 1)$
HNLP

$(\operatorname{trt} 2)$
LNHP

$(\operatorname{trt} 3)$
HNHP

$(\operatorname{trt} 4)$
P-value ${ }^{B}$

0.595

$47.7 \pm 3.8 \quad 49.3 \pm 3.5 \quad 51.7 \pm 4.2 \quad 51.9 \pm 4.9$

$14.4 \pm 1.4 \quad 13.0 \pm 1.7 \quad 14.5 \pm 1.0 \quad 13.3 \pm 1.6 \quad 0.699$

$14.4 \pm 1.4 \quad 13.0 \pm 1.7 \quad 14.5 \pm 1.0 \quad 13.3 \pm 1.6 \quad 0.699$

$21.1 \pm 5.1 \quad 22.1 \pm 4.7 \quad 15.7 \pm 3.5 \quad 19.5 \pm 5.3$

0.837

$16.8 \pm 1.6 \quad 15.5 \pm 1.8 \quad 18.1 \pm 2.0 \quad 16.8 \pm 1.7$

0.944 
C.

$\begin{array}{lrrrrr} & \text { LNLP } & \text { HNLP } & \text { LNHP } & \text { HNHP } & \text { P-value }^{B} \\ & (\operatorname{trt} 1) & (\operatorname{trt} 2) & (\operatorname{trt} 3) & (\operatorname{trt} 4) & \end{array}$

Orthotropic Shoot $\%$

$$
62.0 \pm 4.3 \quad 62.3 \pm 3.7 \quad 66.2 \pm 3.7 \quad 65.2 \pm 5.0 \quad 0.842
$$

Entire Shoot \%

$83.1 \pm 1.6$

$84.5 \pm 1.5$

$81.9 \pm 2.0$

$84.7 \pm 2.2$

0.916

Roots \%

$16.9 \pm 1.6$

$15.5 \pm 1.8$

$18.1 \pm 2.0$

$16.8 \pm 1.7$

0.944

${ }^{\mathrm{A}}=\mathrm{ANOVA},{ }^{\mathrm{B}}=$ Kruskall-Wallis 
Table 2.4. Biomass allocation to different plant parts. Mean \pm one standard deviation of percentage per treatment. Total new biomass includes new culms, HSs and inflorescences that have been produced.

Variable

Culms/total new

biomass

HS/total new biomass

Inflorescences/total

new biomass

Inflorescences/total aerial shoots
LNLP

$(\operatorname{trt} 1)$

$44 \pm 6(12)$

$39 \pm 10(12)$

$17 \pm 7(12)$

HNLP

(trt2)

LNHP

$(\operatorname{trt} 3)$

$46 \pm 15(12)$

$40 \pm 9(12)$

$39 \pm 8(12)$

$40 \pm 18(12)$
$35 \pm 9(12) \quad 41 \pm 7(12)$

$19 \pm 7(12) \quad 25 \pm 9(12) \quad 20 \pm 5(12)$

$46 \pm 21(12) \quad 70 \pm 43(12) \quad 55 \pm 17(12)$ 
Table 2.5. Data from fertilization experiment has been combined and compared to field data from Fall (October 2003) and Spring (April 2004). Mean \pm 1 S.E. Summary of one way analysis of variance for treatment effects on plant growth. Degrees of freedom $=2$.

Significant results $=P<0.05) . N_{f}=30, N_{s p}=30, N_{g}=48$

$\begin{array}{lllll}\text { Variable } & \text { Fall } & \text { Fertilization } & \text { F } & \text { P-value }\end{array}$

$\begin{array}{lccccc}\begin{array}{l}\text { Culm diameter } \\ (\mathrm{mm})\end{array} & 1.61 \pm 0.04 & 1.31 \pm 0.02 & 1.79 \pm 0.03 & 78.381 & <0.00 \\ & (\mathrm{~N}=52) & (\mathrm{N}=84) & (\mathrm{N}=118) & & \\ \text { Hs length }(\mathrm{cm}) & 141.9 \pm 12.77 & 98.23 \pm 7.88 & 111.81 \pm 2.26 & 10.298 & <0.00 \\ & (\mathrm{~N}=30) & (\mathrm{N}=30) & (\mathrm{N}=120) & & \\ \begin{array}{l}\text { Number of } \\ \text { internodes per }\end{array} & 5.87 \pm 0.22 & 4.70 \pm 0.16 & 5.93 \pm 0.07 & & \\ \begin{array}{l}\text { hs } \\ \text { Length of }\end{array} & (\mathrm{N}=30) & (\mathrm{N}=30) & (\mathrm{N}=120) & 23.719 & <0.00 \\ \begin{array}{l}\text { internodes } \\ \text { (mm) }\end{array} & 24.19 \pm 1.40 & 20.90 \pm 1.31 & 18.27 \pm 0.49 & & \\ \begin{array}{l}\text { Length of } \\ \text { internode 2 } \\ \text { (mm) }\end{array} & 17.43 \pm 2.98 & 24.77 \pm 2.58 & 23.57 \pm 1.03 & & <0.05 \\ & (\mathrm{~N}=30) & (\mathrm{N}=30) & (\mathrm{N}=120) & 3.223 & <0.042)\end{array}$


Figure 2.1. Biomass allocation in different structures. Data was summed across all treatments.

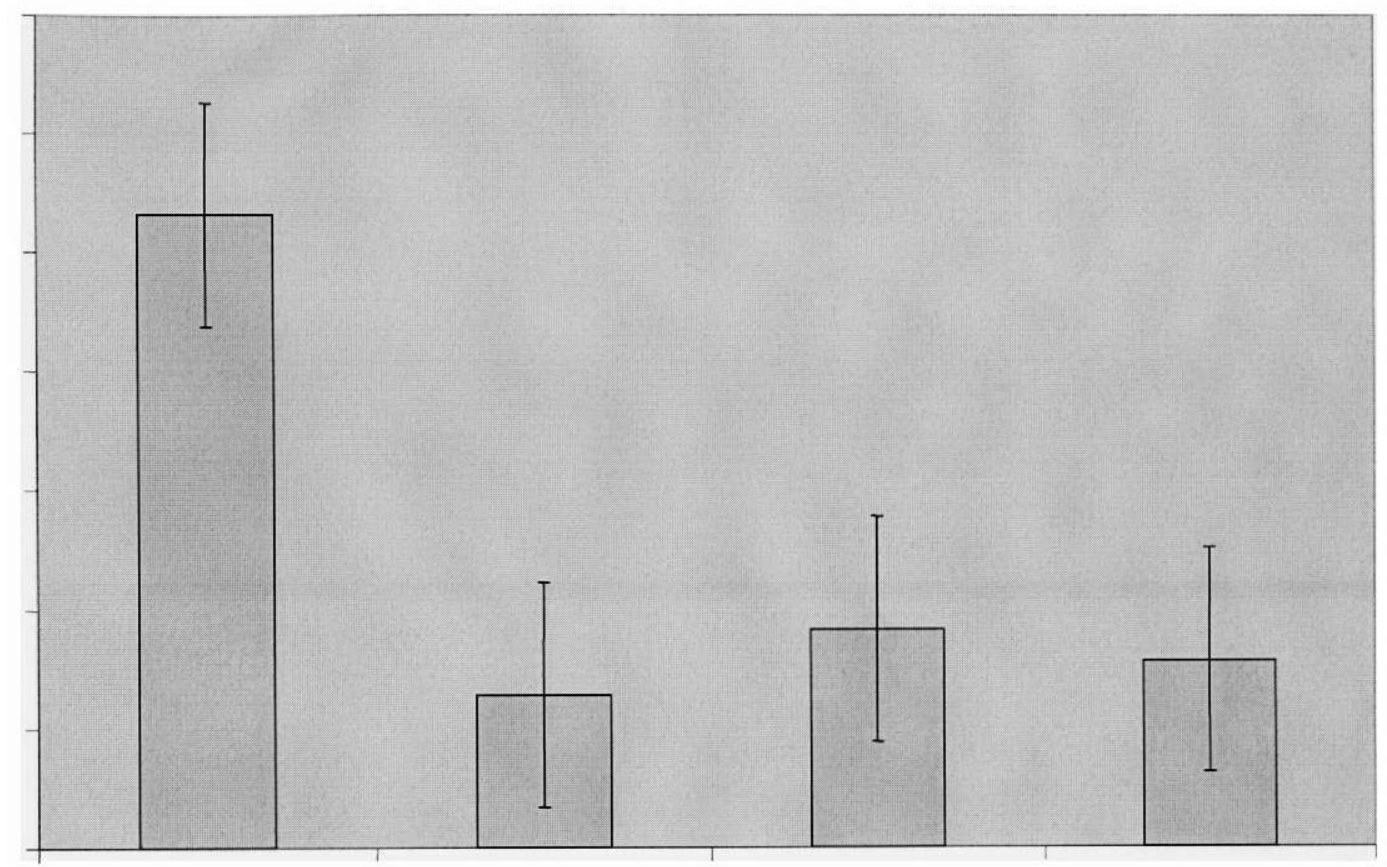

